\title{
Survey of Neurobiology
}

\section{COMMITTEE ON NEUROBIOLOGY}

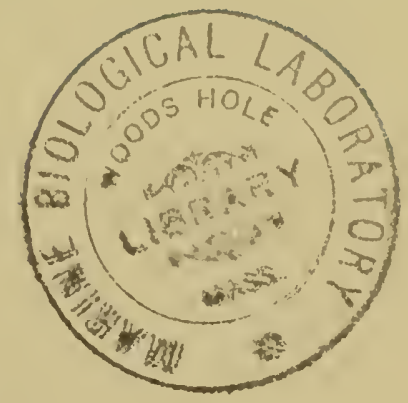

\section{Mational Academy of Sciencesm}

\section{National Researah Council}


Copies of the Annotated Bibliography of Genetic

Neurology (see page 4) may be ordered by returning the order blank below or by writing to:

Publications Office National Research Council 2101 Constitution Avenue, N.W. Washington 25, D. C.

Price $\$ 1.00$

$19 \ldots .$.

Publications Office

National Research Council

2101 Constitution Avenue, N. W.

Washington 25, D. C.

Please send me ................. copies of the

Annotated Bibliography of Genetic Neurology.

$\square \quad \$ 1.00$ per copy enclosed.

$\square \quad$ Please bill me at the rate of $\$ 1.00$ per copy.

Name.

Address 


\title{
Survey of Neurobiology
}

\author{
COMMITTEE ON NEUROBIOLOGY \\ of the
}

NATIONAL RESEARCH COUNCIL

Philip Bard

Detlev W. Bronk

Sam L. Clark

Karl S. Lashley

Wilder Penfield

Paul Weiss, Chairman

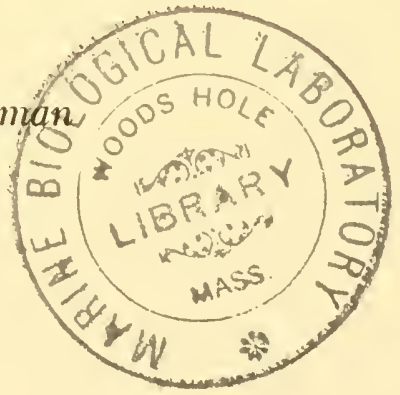

Publication 237

National Academy of Sciences-National Research Council Washington, D. C. 



\section{PREFACE}

IN 1945, Dr. Ross G. Harrison, then Chairman of the National Research Council, recognizing the wide community of interests among students of the many diverse aspects of the nervous system and behavior, called a conference to examine how the common interests of neurobiology could best be served. Upon the recommendation of this conference, the NRC appointed a Committee on Neurobiology to survey the status and needs in all areas concerned with research on the nervous system and to make appropriate recommendations for the promotion of this field. In carrying out its mandate, the Committee, operating under the chairmanship of D. W. Bronk until 1947 and of the present chairman thereafter, has collected pertinent data and opinions. In periodic meetings, including a two-day symposium, the assembled information was critically reviewed. In the end, each member of the Committee undertook to write a summary evaluation of neurobiology from the viewpoint of his particular specialty in the light of the preceding joint discussions of the whole Committee. These condensed reports, which contain the gist of the conclusions and recommendations reached by the Committee, are presented herewith. It was deemed preferable to preserve the individuality of these contributions by publishing them in their original forms, rather than to combine them into a single master report.

The Committee has been aided in its work by a generous grant from the John and Mary R. Markle Foundation, whose assistance is gratefully acknowledged. The Committee members are also greatly indebted to the many fellow scientists who liberally responded to requests for data, advice and opinions. Lastly, the Committee wishes to express its appreciation to all the officers and personnel of the NRC who in their endeavor to serve the cause of science by serving the working scien- tists facilitated greatly the work of the Committee, including the preparation and publication of this report.

The original task of the Committee has been outlined in a memorandum summarizing the conclusions of the inaugurating conference. By way of introduction, the text of this memorandum is reproduced here in an abbreviated and slightly revised version.

\section{MEMORANDUM ON NEUROBIOLOGY}

Preamble

There has been much evidence in recent years of the emergence of an integrated biology of man, bringing biological, anthropological, psychological and sociological knowledge to bear on a rational understanding of the nature and conduct of man. War and postwar problems have intensificd the awareness of a nced for better rational understanding of human behavior. In fact, part of the blame for the existing troubled world situation has been placed upon the discrepancy between the advanced stage of the physical sciences and technology on the one hand, and the rather backward state of our knowledge of man on the other. Since human behavior, or at least that side of it which lies within the province of the sciences, is basically the manifestation of the activities of the nervous system, this implies an indictment of all sciences dealing with the nervous system. This indictment is not altogether unjustified as the nervous system has actually failed to receive attention and investigation commensurate to its paramount importance in human affairs.

In an effort to determine what steps might be taken to rectify this disproportion, the NRC convoked a conference of men prominent in research on the nervous system. This conference was held on June 29, I945 and attended by the following: Philip Bard; Donald Barron; Leonard Carmichael, chairman; Sam L. Clark; John F. Fulton; Robert F. Griggs; Ross G. Harrison; Joseph C. Hinsey; Karl S. Lashley; Rafael Lorente de Nó; Walter R. Miles; Irvine H. Page; Francis O. Schmitt; Lewis H. Weed; Paul Weiss.

The deliberations of this conference made it clear that, in spite of the splendid achievements in various lines of research, the state of the field 
as a whole is deplorably lagging behind the mark which it could attain if given proper focus, encouragement and support. The following summary is a very condensed digest of the main conclusions reached by the conference. For brevity, the field as a whole will be referred to as "neurobiology."

\section{BACKGROUND}

Past Development-Research on the nervous system has followed the lines of specialized techniques, and therefore, has become highly departmentalized, with the various lines, such as physiology, psychology, anatomy, histology, embryology, clinical neurology, psychiatry, neurosurgery, and comparative biology, following, for the most part, independent courses. Lack of cross correlation of information and the reliance upon excessive superstructures of speculation, built upon narrow and often shaky foundations of fact, have led to serious incongruities among the views prevailing in the various separate disciplines, all purportedly pertaining to the same nervous system. Inconsistencies and incompatibilities within each field and among the various fields have provided us with a confused, rather than unified, concept of the nervous system, its construction, function, development and diseases. There is a serious danger in attempting to base psychological, anthropological, psychiatric and sociological theories of far reaching practical implications on neurological foundations the security of which is open to question. At the conference, many examples were cited of psychological and educational theories, either erected with disregard for, and in conflict with, well founded biological and neurological facts, or based on neurological concepts of doubtful validity. The same applies to some of the concepts of health and disease of the nervous system. The amount of human effort and energy misdirected and wasted in this manner in the past is in such disproportion to the comparatively small expense of a concerted effort at consolidating the scientific foundations of neurology, that the latter course commends itself not only for academic reasons, but on economic and humanitarian grounds.

Present Trends-Existing deficiencies are of two kinds: of investigation, and of correlation and integration. A survey of the non-clinical literature in neurobiological fields for the period of 19251945 has revealed, aside from a general slump since 1939 in consequence of the war, that except for physiology, none of the various fields has continused to grow in proportion to either its signifieance or the general expansion of scientific research [sce the sample statistics at the end of this booklet]. It was the consensus of the members of the conference, competent to speak for their respective fields, that we possess only rudimentary and inadequate information about the finer structural anatomy, cytology, physical chemistry, chemical composition, physical structure, functional organization, developmental mechanisms, and regenerative and adjustive powers of the nervous system. In most of these fields, modern and promising methods of research are available but are not being exploited to best advantage. There are further important lines which have remained almost unexplored, at least so far as systematic fundamental approach is concerned; for example, mode of drug action; biochemistry, particularly, differential chemical properties in relation to brain function; immunology; genetics of normal and diseased neural functions; analysis of the development of behavior; etc. All of these fields can point to some examples of important past achievements, but these have remained pathetically small islands in a vast sea of ignorance. In other fields, much of the information gathered has been of purely descriptive character, untouched by any of the modern analytical, experimental methods that could have been readily applied. Many specific cases were cited by the conference in support of these statements. Rarely has a group of experts been so unanimous in professing the shortcomings of their respective fields, and so conscious of the need for a strong forward-looking policy of fundamental research.

Only part of the deficiencies in neurobiology are attributable to lack of adequate information and knowledge. A large part can be blamed on the failure to evaluate, correlate and integrate properly the available knowledge so that different lines of research might utilize each other's sourccs of information, techniques and results to best mutual advantage. In this matter there has been a very healthy change for the better during recent years-a change, however, which in order to become fully effective, requires more encouragement and support than it now receives. Integrative effort may take the form of either active cooperation between specialists of various methods in the study of common problems, or only of correlation and joint interprctation of data obtained independently in the various lines of specialization. The single example of the correlation of experimental, clinical and observational data on functional localization in the brain, obtained from such differcnt lines as anatomy, electrocncephalography, action of drugs, injuries and tumors of the brain, psychiatry in conjunction with neuropathology, and experimental psychology, may serve as one illustration for many. To stimulate and facilitate better and wider correlation among the various lines of specialization, one could en- 
visage the encouragement of conjoint research projects, exchange of students and research work(rs, conjoint course programs, special bibliographic and publication devices, and the like. The conference considered concrete measures that might be taken for the mutual benefit of both fundamental and clinical neurobiology. It also stressed the necessity of making borderline fields more attractive to young research men.

Future Action-Conscious of the situation as outlined in the preceding passages, and aware of the need for constructive remedial action, the nembers of the conference felt that, in view of the complexity and the far reaching implications of the problem, it would be unwise to consider any definite measures pending a much more careful and systematic investigation of the present and prospective needs and facilities for neurobiological research. The conference, therefore, recommended to the NRC "the appointment of a committce to survey the field in order to determine and recommend to the Council such action as may further the development of education and fundimental research on the nervous system."

\section{SCOPE OF SURVEY}

The Committee was charged with investigating if, where, and what sort of action on a national scale would be desirable. The committee was to take stock of the situation by consulation with fellow scientists in laboratories and clinics and to collect and articulate the prevailing viewpoints and interests. Specifically, the following problens were decmed in need of exploration:

(1) Survey of ficlds of research: Since sources of information regarding the nervous system are wiclely scattered and often to be found in unsuspected areas (e.g., insect control by DDT; studies on asymmetry and handedness in identical twins), a comprehensive listing of fields that would contribute to, and benefit from, concerted neurobiological rescarch should be prepared.

(2) Survey of personnel: A list of individuals engalged in research pertaining to neurobiology and of societies representing allied interests, to supplement item (1).

(3) Survey of trends and gaps: Attempts to (a) extrapolate from the recent history of the various specialties their prospective needs in the near future; (b) estimate their various efficiency rates, i.e., ratio of input in personnel, plant, funds, etc. to rate of progress; (c) detect neglected and "underprivileged" lines in need of promotion.

(t) Survey of existing research facilities (exclusive of personnel treated under (2): Facilities of plint; of technical equipment; endowment; institutional, foundational and public support; as- sistance; location (e.g., proximity between laboratory and clinic; between primate laboratories and neurosurgical centers; antivivisectionist restrictions; etc.).

(5) Survey of existing training facilities: Determination of the place of neurobiological disciplines in the curricula of major universities and medical schools; also, matters of postdoctorate training; training of technicians; fellowships.

(6) Survey of channels of communication: Listing of cxisting periodicals; reviews and abstract journals; bulletin services; editorial policies; costs, distribution and availability of publications. Survey of facilities for personal communication; seminars; regular society meetings; special symposia; lectureships; exchange of personnel.

(7) Survey of needs: Collection of opinions and suggestions regarding possible concrcte improvements and innovations of technical, educational, and organizational nature that would promise to insure a more rapid, systematic and efficient development of neurobiology; essentially, a determination of the difference between desirable facilities and those currently available under items (1) to (6).

(8) Survey of potential resources: Estimation of the costs of the developments envisaged under ( 7 ) and exploration of potential sources for the required funds, including prospects of public support.

\section{CONCLUSIONS}

Only at the end of such a survey, could the Committce hope to be in a position to assess judicionsly the basic needs of future neurobiological research, and to formulate recommendations for a comprehensive and integrated program of promotion, with the ultimate aim of a better scientific understanding of the human mind and human behavior. The findings of the Committee were to be made available to all medical, educational, governmental, philanthropic and other institutions that might be concerned with the results.

A comparison between the ideal task of the Committee on Neurobiology, as set forth in this memorandum, and its real attainments, as summarized in the following report, will indicate that the latter have remained somewhat short of the goal, for reasons inherent in the novelty, complexity and magnitude of the task. Yet the Committee feels that it has at least broken ground for future more comprehensive actions in the interest of integration of efforts in matters pertaining to the nervous system and behavior. 
As a sample of the many practical measures advocated by the Committee, an extensive annotated bibliography of one of the branches of neurobiology, genetic neurology, has been compiled under the supervision of the Chairman of the Committee by Agnes S. Burt, M.D., Ph.D. Copies of this bibliography will soon be available at nominal charge from the National Research Council.

Paul WeIss, Chairman, Committee on Neurobiology.

October, 1952 


\title{
NEUROPHYSIOLOGY: STATUS, TRENDS AND NEEDS
}

\author{
By Philip Bard \\ School of Medicine, The Johns Hopkins University
}

IT Is NoT easy to define neurophysiology in terms that sharply distinguish it from other branches of neurobiology. Perhaps one may begin with Sherrington's statement that the nerve impulse is "the universal currency of the nervous system." Apart from mediating in some undetermined manner the trophic influence exerted by the nerve cell body on all parts of the neuron, the only known function of mature neurons is to conduct impulses which have specific effects on effector organs or on other neurons. Neurophysiology is primarily concerned with nerve impulses whether they course in peripheral nerves or through the complex channels of the central nervous system. The neurophysiologist of today has the same regard for his knowledge of nerve conduction that the immediate followers of William Harvey had for the demonstration that the blood circulates because of the motions of the heart. It is with this basic knowledge that he proceeds to analyze further the properties of the individual neuron or to consider the ways in which countless neurons within the central nervous system determine the behavior of the organism. Thus one may very simply depict but not adequatcly define the subject.

At the present time active interest in the experimental exploration of the functional aspects of the nervous system seems to be satisfactory in the sense that during the last twenty-five years this field of research has recruited its fair share of investigators. Although many of these were trained primarily in physiology it is significant that some of the most outstanding contributions to neurophysiology have been made by workers who are the products of other disciplines. Conspicuous among these are individuals who began their scientific careers in physics, in psychology, or in either de- scriptive or experimental morphology. There are also many contributors to the subject who appropriately continue to be classed as zoologists, anatomists, biophysicists, psychologists or neurosurgeons. This heterogeneity of the sources of neurophysiological information emphasizes the fundamental unity of the several subdivisions of neurobiology. It has doubtless produced a certain degree of hybrid vigor, a point that should be taken into consideration in any selection of the progenitors of the neurophysiology of the future.

\section{PRESENT TRENDS AND NEEDS}

1. The Mechanism of Conduction of the Nerve Impulse. This fundamental branch of neurophysiology developed rapidly in the 1920s and attained a high plateau of achievement in the work of Erlanger and Gasser. Interest has continued and there is little basis to fear that it will be neglected. The recent and current activities of Hodgkin, of Curtis and Cole, of Lorente de Nó and many others suggest that the remaining mysteries of the local excitatory state as well as those of the mechanism of propagation of excitation along the neuron may be substantially reduced in the near future. In this sphere perhaps the least understood aspect is the way in which energy is made available for conduction, particularly for the restitution of the resting potential. It appears that the techniques of the enzyme chemists are not yet adequate to determine with assurance the specific chemical changes, but recent experimental results which relate the resting and action potentials to chemical sources of energy and transport of ions provide assurance that very significant advances are being made.

2. The Physiology of the Synapse. This topic includes the problem of the transmis- 
sion of excitation at the neuromyal junction as well as at synapses in autonomic ganglia and in the central nervous system. It also is one that is being studied intensively by a number of highly competent investigators. It can be said that the classic analyses of the reflex arc, carried out by Sherrington and his students, are being elaborated by the use of still more potent techniques. The old question of the nature of central excitation and inhibition remains unanswered, but it should be noted that the attack continues. Certainly the problem has been well outlined and much useful information has been obtained by recording potential changes, both slow and rapid, from gross electrodes on or in the cord and on spinal roots, but the interpretation of some of the results has been both difficult and varied. Very recent studies by Eccles in which potential changes within the somata of individual spinal neurons were recorded are apt to limit and reshape some of our thinking about the intimate character of synaptic processes. It is reasonable to suppose that the extension of this technique and the further testing, at the subcellular level, of the hypothesis that basically both excitation and inhibition are mediated by chemical transmitters will lead to a substantial "break-through" in neurophysiology.

3. Studies of Single Units. Although these have contributed greatly to those branches of neurophysiology referred to in paragraphs 1 and 2, they deserve separate consideration. Directed toward an analysis of the properties and activity of the indiviclual neuron, such studies are the physiological counterpart of those microscopic investigations that led to the concept that the neuron is the genetic and anatomical unit of the nervous system. At the hands of Adrian and Bronk and their students and followers, the direct recording of the electrical activity of single sensory and motor fibers gave further evidence of the all-or-none character of the response of neurons, provided a picture of how sense organs act in response to stimuli, demonstrated a parallelism between the intensity of an environmental stimulus and the num- ber of afferent impulses reaching the central nervous system, and showed that frequency of discharge in single motor neurons is one way in which the magnitude of an effector response is graded. The achievement of following the activity of single units in the peripheral portions of the auditory and visual systems indicated that this method may be extended to the more complex reaches of the nervous system. It should be borne in mind that recent work on cerebral mechanisms has been guided and interpreted in terms of results obtained by analyses of units in peripheral nerves and in autonomic ganglia.

Quite recently the electrical responses of single thalamic neurons evoked by physiological stimulation of cutaneous and deep receptors of the limbs have been recorded. The results already obtained show that the method employed is well adapted for analyses of the functional organization of the central mechanisins underlying several somatic sensory modalities. Somewhat similar techniques are being applied in studies of units in the cerebellar and cerebral cortices. They will doubtless reveal information that cannot possibly be obtained by the relatively crude techniques of electroencephalography.

Several suggestions have been put forivard to the effect that activities within the central nervous system are determined by a mode of transmission that is extraneuronal. While it would be undesirable to ignore this possibility it seems wise to conclude that further advances in our understanding of cerebral functions will depend primarily on the testing of hypotheses that envisage central activity in terms of fiber conduction and synaptic transmission.

4. Transmission, Interaction and Control of Reflexes. A definite advance was made when Lloyd succeeded in dissecting the segmental reflex discharge into its functional components. The disclosure that impulses in certain afferent fibers of muscular origin activate a two-neuron arc while impulses in others travel a path involving interneurons led to work which has given a better understanding of the basic organization of spinal reflexes, of 
the interaction of reflexes and of the relation of various receptors to reflex motor acts. The existence of self-limiting activity in reflex action has been recognized but much of importance remains to be discovered concerning the mechanisms involved. The discovery by Kuffler of the control of muscle spindle discharge by the small fiber component of the ventral roots has added substantially to our present concepts of how the central nervous system regulates the tonic and phasic activities of skeletal muscle. Our understanding of the supraspinal control of segmental reflexes was greatly expanded by Magoun's elucidation of bulbar and brain stem areas which exert excitatory and inhibitory influences at the spinal level. Considerable progress has been made in determining the cerebral and cerebellar control of these areas. In this connection it should be noted that the significance of the so-called suppressor bands of the cerebral cortex is by no means clear. It is possible that in certain instances the inhibitory effects evoked from them were conditioned by the state of anesthesia. In general it can be said that many stimulation experiments should be repeated, if possible, without the complication of general anesthesia.

5. Electrophysiological Analyses of Cerebral Organization. These are of relatively recent origin and constitute a large fraction of current studies of the brain. The actual methods used have been of several kinds and have been directed toward somewhat different ends. Except for the well known technique of electroencephalography each of these methods involves the recording of electrical changes induced by stimulation at the periphery or at a distance within the central nervous system. Physiological neuronography, introduced by Dusser de Barenne and McCulloch, is based on evidence that the local application of strychnine to a gray mass causes large sudden voltages (strychnine spikes) to appear in all places where axons of cells situated in the strychninized region terminate. The method has been used extensively to determine neuronal connections and it has doubtless provided some useful information regarding intracortical connections and connections betwcen cortical and subcortical regions. The assumption, widely held, that where and if impulses set up by strychnine cross synapses they become asynchronous and so undetectable may be questioned, and if it should prove even partly erroneous many of the conclusions that have been drawn will have to be revised. In any case, activation of neurons by strychnine appears to have the advantage over electrical stimulation that it does not set up antidromic conduction and does not produce an electrical artefact that may make electrical recording difficult or impossible. Another relatively new procedure is the determination of the central representations of sensory modalities by recording potentials evoked by appropriate stimulation of sensory surfaces. The application of this method has made it possible to map in great topographical detail the major sensory areas of the cerebral cortex, to demonstrate that several sensory modalities have specific representations in the cerebellar cortex, and to show that tactile sensibility has a detailed topographical pattern of representation in the thalamus and the dorsal column nuclei. The method has led to some unexpected results which will doubtless prove to be of importance. The discovery that the tactile, visual and auditory systems have a definite cerebellar representation is one of these. Another is that there are two complete and separate sensory projection areas for touch, vision and audition in the cerebral cortex of mammals. The functional significance of these two facts remains to be determined.

\section{Anatomical and Physiological Correla-} tions. It is well recognized that many neuroanatomical facts are devoid of functional significance. For example, there are conspicuous fiber tracts within the central nervous system to which no function can be assigned. It is desirable that modern methods of neurophysiology be employed in attempts to dispel this ignorance. On the other hand, plyysiological studies have revealed the existence of functional connections for which there appears to be no known anatomical basis. Thus the two dis- 
ciplines provide one another with a number of interesting and provocative problems. It is clear that they can best be solved by the cooperative efforts of neurophysiologists and neuroanatomists. There are many other ways in which cooperation between these two subdivisions of neurobiology may lead to advances. One of these might well be a fresh attack on the problem of the relation of cytoarehitectural fields of the cerebral cortex to functionally defined areas and to the thalamic nuclei. Such an attack could well be carried out by comparing the cortical fields with the sensory areas mapped by the method of evoked potentials. Already studies have been undertaken to determine the thalamic degenerations resulting from precise ablations of the several mapped areas.

In this connection one should draw attention to the considerable masses of gray matter which cannot be assigned any specific function. Foremost among these are parts of the so-called rhinencephalon, especially the hippocampal formation and portions of the amygdaloid complex. There is no valid evidence that these structures subserve olfactory functions and there are good reasons for supposing that they are not parts of the "smell brain." Here anatomical description is far ahead of physiological analysis.

7. Comparative Studies. Comparative neurophysiology is a neglected subject. This is a most unfortunate state of affairs, for there are reasons to believe that comparative studies may yield information that cannot be obtained in any other way. In the evolution of the mammalian series the central nervous system underwent a development that is far beyond that of any other organ system. The eardiovasenlar systems of dog and man differ only in minor details. The brains of these two species differ markedly. It is therefore far easier to apply experimental results obtained on the dog's heart to the problems of eardiology than it is to use "log neurology" in the elucidation of the functions of the human brain. When, however, a specific aspect of cerebral organization is studied systematically in a series of mammals, say, from marsupial to monkey, species differences become less striking, a fairly smooth curve can be plotted and an "extrapolation" to man is likely to yield a good working hypothesis. When Woolsey and his collaborators had mapped the sensory areas of the cortex in a small number of diverse species by the method of recording evoked potentials, they were able to make correct predictions as to the loci of the areas in the brains of intermediate and "higher" forms. At the same time the results established for the first time homologies between the widely differing fissures of the different species. Such results suggest that much of value will be obtained when similar comparative studies are carried out.

8. Analysis of Cerebral Mechanisms Involved in Various Modes of Behavior by the Method of Surgical Ablation. It has been established that many coordinated and patterned acts depend on specific central mechanisms that lie within sharply bounded portions of the brain. Although destruction of the delimited region permanently abolishes all possibility of evoking the total response, some items of the pattern may still be elicited. Further, with the essential region intact it is usually easy to show that other parts of the brain exert modifying influences upon it. This can be most readily demonstrated by surgical procedures. The result usually suggests the operation of a series of ehecks and balances. At this point other techniques might be employed to advantage as has been done in certain instances, notably in the case of the respiratory center.

In neurophysiology the method of ablation is an old one, but it remains useful and it has undergone numerous refinements, thanks to the influence of the neurosurgeons. It has thrown light on the neural bases of both stereotyped and learned modes of behavior. It appears that it may be useful in analyzing still more complex central mechanisms. In man frontal lobotomies and "topectomies" may produce extraordinary changes when a deep-seated disorder is present. It is not known why these effects are produced. Results already obtained on animals sug- 
gest that in them marked alterations of a comparable nature can be reproduced by certain cerebral ablations. The desirability of pushing animal experimentation along these lines is obvious. In such work the neurophysiologist will require the cooperation of the psychologist just as the neurosurgeon requires the collaboration of the psychiatrist.

9. Other Problems. There remain many other activities of neurophysiologists to consider. The problems and trends described above are merely ones which the writer believes worthy of special attention at the present time.

\section{THE TRAINING OF NEUROPHYSIOLOGISTS}

The investigator of the functions of the nervous system must possess a competency in the use of at least two or three techniques and have some understanding of other methods of study. The major techniques that seem to be required for further advances are the surgical, the electrophysiological, the chemical and the anatomical. Each of these may be divided into several categories. A few examples may be given. It is one thing to decerebrate a cat or dog and study the preparation briefly in the manner of Sherrington and Magnus; it is quite a different matter to decerebrate an animal and keep it alive and in good condition for five months. It is now not difficult to obtain and maintain - with the help of experts in electronicsequipment that permits the recording of localized potential changes evoked in the cerebral cortex when certain sensory surfaces are locally and discretely stimulated, but it would require advanced knowledge of electronics on the part of the neurophysiologist himself to push the electrical analysis of sensory cortical function further, say, to the point of scanning the activities of any specific sensory area when it is activated by stimuli having some temporal and spatial complexity. It is not difficult for the beginner to determine grossly and to describe in general terms the effects of anoxia on the central nervous system, but the analysis of the intimate effects of oxygen lack on individual neurons or on a specific neuron system requires technical facilities and a competence to use them that can only be obtained by training in the higher echelons of modern physics and chemistry. Finally, it should be pointed out that the results of the application of many neurophysiological methods must be considered in the light of either an anatomical control or of a careful correlation with established anatomical facts.

These examples may serve to emphasize the difficulties that confront the student beginning a career in neurophysiology. He is not likely to find opportunities for experience in several techniques in any one laboratory or department. Further, in the mastering of one of the more complex tools of investigation the student always runs the risk of becoming a narrow specialist who is so dependent upon and so enthusiastic about his technique that his selection of problems will be almost wholly determined by the applicability of a single method of attack. Probably the most effective way of preventing this perversion in training is to provide attractive postdoctoral fellowships that will enable the young investigator to spend several years in different laboratories. The need for this kind of support is great and it will become greater in the near future.

However great our concern may be for the proper training of neurophysiologists this problem is secondary to that of attracting into the field the best available material. Anyone who has had experience with medical students knows that many a potentially fine investigator is lost to the basic sciences because, in the face of economic difficulties, a career in a clinical field seems so much more feasible. This is a problem that neurobiology shares with all other basic sciences related to medicine. Doubtless added inducements, if properly directed, would serve to recruit more first-rate material. 


\title{
TRENDS AND NEEDS IN NEUROANATOMY
}

\author{
By Sam L. Clark \\ Vanderbilt Medical School, Vanderbilt University
}

William Harvey in the dedication of his Anatomical Studies on the Motion of the Heart and Blood declared "many ... maintain that all we know is still infinitely less than all that still remains unknown." Through the more than three hundred years since this statement was made much has been learned but the statement remains essentially true. To attempt therefore to point out the direction research should take to fill the gaps in knowledge of the nervous system from the neuroanatomical viewpoint is a formidable if not a presumptious task, and provokes sympathetic understanding of the dilemma of the poet viewing the "flower in the crannied wall."

Significant to the problem of what is and is not known in neuroanatomy is the question of who is contributing to the field. Neuroanatomy as a course is taught for the most part in medical school, but not all who teach it are involved in investigation of the nervous system. Among the members of the American Association of Anatomists there are very few more neuroanatomists than there are medical schools in the country; those contributing to neuroanatomical knowledge, however, include many who are physiologists, zoologists, psychologists, pathologists, neurosurgeons and others less obviously related to the field. The overlapping is unavoidable and fortunate since these various workers have brought to bear on the nervous system a wide range of interests and have pointed out morphological details with tools that range from a stick whittled out of orange wood to the inertialess beam of the cathode-ray oscilloscope. It is difficult for the indiviclual specialists to stick to their fields, for the form and function of the nervous system are so intricately bound together that the investigator of function finds it necessary to unravel details of morphology; and the anatomically minded student must of necessity consider physiology. From the way the nervous system is constructed for conduction it is frequently possible to interpret the function of a pathway or "center" by determining its connections.

\section{TERMINOLOGY}

In any field the ability of workers to communicate with each other is constantly dependent upon the speech they employ, and each group has, as it were, its own vernacular or terminology. Such terminology is not static but changes with developments of knowledge. A serious need in neuroanatomy, and no doubt in other neurobiological fields also, is an active commission or some other suitable method for selection or acceptance of what appears to be the best terminology. The current activity of the International Committee on Anatomical Nomenclature promises help in this direction.

Historically, problems of form and function of the nervous system have been investigated together (giving unintended strength to such unscientific offshoots as phrenology) and a nomenclature developed emphasizing this. But due to the slowness with which complete and accurate knowledge accumulates, conflicts were created and the terminology adopted often implied functional relationships not supported by subsequent investigation. We have become accustomed to such discrepancies and ignore the original significance of some terms, as: pituitary gland, optic thalamus; but we are more or less unconsciously restricted by others, as, for example: motor area, respiratory center. $\Lambda_{n}$ example of the importance of proper terminology for understanding is found in names of parts related to visceral innervation. That word of good character when 
used in ordinary speech, "sympathetic," becomes in neuroanatomical nomenclature a symbol of confusion and antagonism unless it is properly modified by phrases which would be quite adequate alone.

It is difficult to do anything about terminology already established, but the christener of newly described structures should proceed with caution, and perhaps hesitate over the selection of even an accurate, purely morphological designation if it is so complicated that only the mnemonically minded student can retain it (e.g.: nucleus ventralis posteromedialis of the lateral thalamic nucleus).

\section{COMPARATIVE ANATOMICAL NEUROLOGY}

Admitting that "the proper study of mankind is man" there is yet much to be learned about him by study of a comparative series of the nervous systems of animals. It has been stated. that the best known animal is the earthworm, but all the details of the nervous system of this animal are not clear. Significant stucties on the nervous system of various invertebrates and of fishes, amphibians, reptiles, birds and mammals have been carried out, but it is safe to assert that not all the desired details in any one animal species have been discovered. There is need for further correlation of activity (behavior) with the neuroanatomy and neurophysiology of each of those animals commonly worked with and for extending the observations to other appropriate forms. For example, the brains of bees and ants would seem entirely inadequate to account for their complicated but well organized behavior. Experiments correlating the structure of the brain in these forms with their activities would be of great importance along with other problems among invertebrates. A type of approach already applied in higher vertebrates, that of removal of parts of the brain and observation of the effects on resultant activity, might be of value in these lower forms and could be used more extensively in lower vertebrates as well. Perhaps highly complex instinctive reactions such as the nesting habits of birds could be analyzed by such means.
The approach by means of experimental embryology now being so well used with salamanders and with chicks to explain the basic principles of development should be applied to more species.

Correlation of normal developmental changes in the nervous system with the earliest appearance of behavior patterns as has been done for amblystoma by Coghill and his followers, for the cat and rat by Windle and his students, and for man by Hooker and others should be continued and extended to other forms. In man closer study of postnatal behavior in relation to maturation and growth of the cerebral cortex is indicated.

In the vertebrates comparative methods of study have made clearer the patterns of cranial nerve components, the connections and significance of tracts and centers, and the significance of suprasegmental structures, cerebellum, tectum, and cerebral hemispheres, but the fields are not entirely harvested. In comparative studies of the gross anatomy of the cerebellum the observations of Tilney and of Larsell correlating the relative size of different portions of the cerebellum with the relative masses of muscle of different body parts have supported localization of representation in the cerebellum, but further work of this kind and its correlation with physiological studies of the living animals is needed.

The relative position of gyri and sulci of the cerebrum and their development in different mammals has aided in interpreting localization of function of the cortex, but this type of analysis, on a gross anatomical level, is not yet fully exploited. Even the significance of the foldings of the cerebral and cerebellar cortex is unknown. The lack of correlation of cytoarchitectonic areas and gross subdivisions offers a field. for further investigation.

The external gross anatomy of man's nervous system would appear to be adequately known, and the greatest needs clo actually lie in this field in better descriptions of brains of other animal species; but there are those who emphasize the possibility of further results to be gained 
from gross dissection of the interior of the human brain. Rosett, and Krieg have lately shown the possibilities in this by different means. Comparative studies of similar type would no doubt be fruitful.

\section{MICROSCOPIC MORPHOLOGY}

The significance of microscopic structure for understanding of function in any tissue became apparent with the establishment of the cell "theory" by Schleiden and Schwann a century ago. With the development of staining methods specific for nervous tissue by Golgi, Cajal and others (arising out of the photographic process of Daguerre) and the application of the cell idea to nervous tissue in the form of "the neuron concept," details of the relationships of individual neurons to each other began to be made available. Needless to say, this mapping of the fundamental units of structure is not even near completion for man's nervous system, much less for that of numerous forms of experimental animals of all types.

There is much to be done of pure descriptive character in practically every part of the nervous system centrally. Why are different nerve cells shaped as they are; why are synapses variously formed as they are; what is the exact relationship of two neurons at synapses other than those only so recently adequately described? Does a "nerve net" as a true syncytial arrangement of neurons ever occur? If so, in what animals, and under what circumstances and in what particular form? How is the morphology of synapses related to the production of humoral substances which are related to nerve impulse transmission? Why does the Nissl material not occur in axons? What is the significance of the various forms of dendrites? Does the recent demonstration that continuous protein synthesis in the nerve cell under influence of nuclear components, and the probable migration of new materials distalward along the axon, complete the story-or only raise more questions as to how the neuron survives throughout a long life without the capacity for unit reproduction? These are only a few of the questions which may be asked about the purely morphological details of neuron structure.

Other parts of the nervous system not made of neurons also require investigation. What is the significance of the form of the various glial types? Are there any more than the three well known ones and the recently included glial cell without processes? What is their exact relationship to neurons and other structures? What is the significance of the rhythmic contraction of certain glial cells demonstrated by motion pictures in tissue culture? Do the satellite and capsule cells of peripheral ganglia and the neurilemmal cells bear the same relationship to peripheral structures? Even the vascular supply of the nervous system, the meninges and chorioid plexuses require further investigation. It would be valuable to know the structural and physiological mechanism involved in the production and maintenance of increased intracranial pressure.

In the periphery, what is the significance to function of the various forms of nerve terminations? How specific are the requirements on the sensory side of both special and general sense organs of the non-neuronal constituents for the achievement of specific sensations?

It would be interesting to know the underlying morphology required which allows the signalling of external stimuli so that they are interpreted as heat, cold, sound, etc. With all that is known of the microscopic structure of the retina the experiments of Hecht, which show that 5 to 8 quanta of light acting over an area containing about 500 rods produce the minimal sensation of vision, lead to a further demand for knowledge of retinal structure.

On the motor side what is the morphological relationship of motor endings to skeletal muscle? Is a paraterminal network once described in the neighborhood of motor endings present or even necessary with the accepted ideas of humoral transmission? It would be valuable to know the actual details of innervation of ordinary cardiac muscle fibers and of the modified ones of the atrio-ventricular bundle.

The inadequacy of descriptions of in- 
nervation of most regions of smooth muscle is apparent. There are evidently differences in different areas since no one has demonstrated a nerve ending for every smooth muscle cell in the walls of the viscera or blood vessels, though each cell of the iris and ciliary muscles appears to have its own ending. Even here the exact relationship of the ending to the cell is disputed, and the relationship of the nerve endings to the production of humoral substances is again a significant question.

There is general agreement that autonomic nerve fibers do not supply skeletal muscle fibers with endings, in mammals at least. But in the eyes of birds (and reptiles) the intrinsic muscles are striated and innervated by a two-neuron chain, the postganglionic cells of which lie in the ciliary ganglion. The difference in form of these neurons, as compared with autonomic cells of the sympathetic trunk ganglion, must be significant. This break in the principle of the relationship of the nervous system to different types of muscle, to be understood, would require detailed comparative studies. If such an arrangement ever occurs in mammals perhaps it would be in border zones such as in the wall of the esophagus where smooth and striated muscle become intermingled. Closer study of such areas is indicated.

When the inquiry into morphology on a microscopic plane is pressed still further there is much to be done to determine the nature of the barrier everywhere between the interior of a neuron and its environment on the one hand, and between the interior of cell "organs" such as nucleus, Golgi apparatus, mitochondria, neurofibrils, etc., and the surrounding cytoplasm on the other. The thinness of the lipoid covering of mitochondria makes one wonder if the forces across these thin membranes are in the high range of those Hardy demonstrated across lipoid films in his study of boundary phenomena in systems outside the body. Even the diameters of various cell organs and calculations of surface tensions displayed in various cell inclusions would seem to be important in the light of D'Arcy Thompson's reminder that as the diameter of a small sphere approaches molecular dimensions the surface tension involved in maintaining its shape is measured in the range of thousands of atmospheres of pressure. In making inquiries concerning the direction of the chromatin of the nucleus, the provocative findings of Delbrück that the gene is very likely a single large protein moleclule containing only about a thousand atoms, make it desirable to know the basis of power of this potent regulator of orderliness in the nervous system. How do such structures reduplicate themselves in cell division? Here and elsewhere the use of the electron microscope will no doubt be of value.

At such levels morphological details are to be studied in terms of chemistry and physics. Knowledge is available from the use of microchemical techniques of the distribution of iron and other inorganic substances in nervous tissue, but the method of micro-incineration has not been completely exploited as a means of studying the distribution of various elements. The use of radioactive substances and the method of having deposits of these show their microscopic distribution by acting upon a superimposed photographic emulsion promises significant results. Distribution of enzyme systems in neurons, so well begun with alkaline and acid phosphatase, offers further promise of the value of microscopic morphology as a field of study. The studies of Caspersson on the distribution of nucleo-proteins in nerve cells have opened new fields.

Alterations as a result of pathological processes both in the chemistry of neurons and their morphology is another means of study needing attention. The method of chromatolysis still yields results under proper control and displays the cells of origin of a cut nerve pathway. The changes produced in the myelin sheath with degeneration have been of great value in tracing pathways by specific staining of the altered myelin, and the method is in constant use. If one could obtain a comparable method of selective staining of axis cylinders, cut loose from the cell hodv and so on the way to degeneration bit not yet frag- 
mented, the whole detailed anatomy of the nervous system could be rewritten and answers given to many current questions. The results of the method analyzing specific differences occuring in boutons terminaux in early stages of. degeneration are not yet sufficiently reliable.

The fact that certain viruses travel along axis cylinders and, as shown by Goodpasture, produce detectable changes in nuclei, cell bodies, and axis cylinders of the neurons involved has not been given sufficient trial as a means of studying connections in the nervous system.

Larger problems of morphology may have their answers at microscopic levels. Dr. Cannon once asked, “Are there 'bushes' and 'trees' among nerve cells and therefore different limits to the possible growth of them?" The accepted fact that nerve fibers grow as the body grows has been taken for granted but the question of how long nerve fibers may be made to grow, or how far they may be stretched, has been raised by the recent successful attempts of Hoen and Bering to fill gaps in damaged nerves by stretching gradually the central stump.

Problems of regeneration include many morphological details which have been well worked out, but there are additional needs. The influence of substances (such as pyrogens) introduced into the body of an animal with central nervous system damage on the possible regeneration of nerve fibers or the inhibition of glial scarring would seem to be a promising field of study. When tumors and new growths arise there is some evidence that they may become innervated, but the factors in this are not clearly known. Transplantation of mature nerve cells both of cerebrospinal and autonomic ganglia into another part of the animal has been accomplished with survival of some cells for long periods of time, but only recently has evidence been produced that mature nerve cells can be successfully transplanted into tissue cultures, where they may even undergo mitosis. Such an observation indicates need of further study of the binucleate cells of ganglia and the possibility of multiplication of nerve cells.

\section{CEREBROSPINAL NERVES}

The problem of segmental innervation of the skin and muscles appears in need of clarification. The need has been emphasized by the variations in mapping of dermatomes as revealed by measurements of skin resistance following sympathetic denervation, in contrast to maps based on cases of herpes zoster, spinal nerve root section, and deeper segmental representation as indicated by injections of saline into interspinous ligaments.

The composition of peripheral nerves is rather well established but the question continually arises as to whether the dorsal roots are purely sensory and the ventral ones purely motor. Suggestive evidence that Bell's law does not hold for dorsal roots appears from physiological experiments, particularly from those recording action potentials; and for the ventral roots from studies on pain in tabes and in individuals with dorsal roots cut. However, the morphological proof in the case of both ventral and dorsal roots is incomplete.

The cranial nerves pose a number of problems, prominent among which are questions arising out of the classification of functional components so well established by the work of American comparative neurologists. There is need for continuing and modifying this classification by close study of comparative anatomical details. Conflicts exist within it, for example, classification as "general somatic afferent" of the proprioceptive fibers supplying muscle sense organs in muscles of mastication which are supplied by motor fibers classed as "special visceral efferent." While this and other problems are partly academic ones due to the use of either one of two separate criteria for classification, there are additional problems to be solved in the location of cell groups concerned with specific functions. For example, little is known of the location of cells giving rise to the proprioceptive fibers of the cranial nerves, except those of the trigeminal. Location of the "salivatory nu- 
clei" is uncertain. Visceral innervation could be studied to advantage with reference to the type of sensation conveyed by the vagus nerve, the evidence of segmental immervation, and the course and termination of secondary pathways conveying visceral sensibility.

\section{GRAY MATTER OF NERVOUS SYSTEM}

In the distribution of gray matter in the nervous system there are certain obvious general trends evident as one examines a whole series of animal forms. There is early in the scheme the centralization of cell bodies, the accumulation into ganglia and then larger masses of central gray matter, the tendency to encephalization, and the associated precocious development of the cranial end of the nervous system. Along the way an endo-skeleton. develops and forms an encasement for the nervous system which comes to lie dorsal to the alimentary tract instead of ventral to it, and explanations of the changes are not entirely adequate. The ingenious theory of the origin of vertebrates by way of the annelids and arthropods requiring that the latter turn over on the back and develop a new mouth because of the enlargement of the nervous parts and the associated constriction of the stomodeum which remains as the hypophysis, has been largely discarded for a theory of origin by way of the echinoderms and hemichordates. But even with adequate description of the stages of transition there still remains the larger question of how and why the nervous system increases in volume and complexity. The question must in part be answered by morphological studies.

Even the general distribution of the masses of gray matter in the nervous system raises questions. The location of some groups of nerve cell bodies has been theoretically explained by the principle of neurobiotaxis, but this requires substantiation. The significance of the peripheral location of autonomic ganglia, and the two-neuron chain between central nervous system and visceral effector, is not entirely clear. There is also the constant question as to whether there exists a complete mechanism for local reflexes in these ganglia. It also would seem to require explanation that most primary afferent neurons lie outside the neuraxis, though a few are within it in the mesencephalic nucleus of the trigeminal nerve, and perhaps other groups occur.

Within the spinal cord and medulla the general principle of segregation of motor and sensory cell groups in alar and basal laminae, and subdivisions of these, has aided in emphasizing the location of cell groups of different functions; but questions remain that may be more difficult to answer if there is strict adherence to these principles of distribution. Evidence from Corbin's work, for example, points to the possible location of proprioceptive cells for intrinsic muscles of the eye in the region of the oculomotor nucleus in the basal lamina. If this is established other proprioceptive cell groups of cranial nerves might be easier to locate, but even more significant to the result would be the general questions as to the accuracy of the terms "sensory" and "motor" as applied to alar and basal laminae.

Even the reasons for segregation of the large mass of gray matter into separate suprasegmental structures, cerebellum, tectum, and cerebrum are not at hand; and within these the localized distribution of representation in specific areas offers opportunity for fruitful investigation. It would be interesting to know why there is greater homolateral representation in the cerebellum and a larger cross representation in the cerebrum, as well as the reasons for the "inverted" representation in the cerebral motor and sensory areas of man. A comparative study of the relative position of the points in the motor area in mammals suggests that the area is swung from an antero-posterior representation to a transverse one as the frontal lobe developed. But we do not know why the frontal association areas developed where they did, other than that old "habit" of the brain of telencephalization.

Aside from an explanation of the reasons involved, it would be good to have 
a systematic study of the topography of representation in different parts of the brain in relation to the orientation of bodily parts. No explanation would appear necessary for such gross arrangements as having the legs innervated by the caudal end of the spinal cord and the arms by the cranial end, or even that the trunk muscles are represented in groups of neurons placed medially in the spinal gray matter and the limb musculature largely laterally. But how far can such correlations be carried, and what would be the predictive value of such work? In the motor area of the cerebrum of lower mammals (for example the goat) the hind limbs are represented posteriorly and the forelegs more anteriorly, and the head and face even more anteriorly though the facial representation spreads laterally. In higher mammals, with the development of the frontal association areas anteriorly and medially, the motor area is pivoted laterally leaving the area for hind legs medial in position. In the motor area of the cat the foreleg representation shows finer topographic orientation. Stimuli applied anteriorly in this area result in protraction of the limb, and stimuli applied more posteriorly result in retraction.

In the auditory area there is an orderliness in representation of octaves along the cortex, with change from high to low pitch being represented progressing posteriorly. In the visual cortex and in the geniculate bodies a topographic orderliness prevails. In the cerebellum response to cortical stimulation shows a topographical representation of a double sort. The head moves toward the side stimulated while the stimulus is in progress but toward the opposite side in rebound when the stimulus ceases. If stimulated in the midline the direction of head movement during stimulation is downward and forward when the stimulus is anterior to the primary fissure, and upward and backward when the stimulus is posterior to this fissure; and in each case the opposite movement occurs in rebound just following stimulation. Removals of approximate halves of the cerebellum, dividing it along sag- ittal or transverse planes, is followed by a sustained tendency to "fall" in the direction in which the intact animal would have moved during stimulation of the part left intact. Explanation of such topographic relationships might go far toward explaining the way in which the nervous system functions.

Evidence exists of similar topographic patterns of representation in the deeper structures of the cerebrum as basal ganglia and thalamus. But what is the situation within the olfactory and gustatory cortex and the cortex concerned with speech, or even that devoted to the phenomena of higher integration of memories and experience which is loosely referred to as thinking? The observations of Penfield that electrical stimuli to the temporal cortex of man can repeatedly elicit conscious recognition of a complicated series of incidents appearing to the patient like the events in a dream raise interesting questions, as he points out in the "Anatomy of Memory." Details of topographical representation along these lines appear to need correlation with Lashley's experiments indicating lack of specificity of cortical representation of function. Further detailed analysis of the relationship of cortical areas related to speech in patients with aphasia is needed.

\section{THE PATHWAYS}

Aside from the facts that might be gleaned from blunt dissection of major bundles of white matter in the brain, almost every pathway that is named or described needs further investigation if it is to be completely known. We are here reminded again of the need for adequate terminology to be applied after accurate knowledge is available of the origin, course, and termination of tracts. Within recent years there has occurred an example of complete reversal in the direction described for a fiber bundle. As the result of experiments, the Ransons converted the strio-nigral bundle to a nigro-striatal one.

Comparative studies on pathways as well as more intensive study of tracts in an individual species are needed. For example, in the descriptions of afferent cerebellar 
connections in lower animals there commonly appear references to exteroceptive fibers from various sources, and even gustatory fibers, that enter the cerebellum; but as soon as the description of the situation in higher vertebrates is encountered reference is made only to proprioceptive connections. Only recently evidence that tactile, auditory, and visual impulses reach the cerebellum has been published, and even some evidence that the cerebellum is not entirely free from relation to pain and to visceral control has been brought forth.

On the afferent side to the cerebrum there is still some question as to the representation of pain in the cortex, so that the site of termination of this important pathway is not known. The exact course and termination of most ascending pathways could be better understood. There is need of further knowledge of the intricate interconnections of parts of the gray masses within the cerebrum, i.e., basal ganglia; and thalamic, subthalamic and hypothalamic nuclei. The large mass of internuncial connections in cord, brain stem, and suprasegmental areas offers endless possibility for investigation, as emphasized by the significance of the reticular system to general problems of inhibition and excitation shown by Magoun and others.

On the efferent side, even that pathway most often discussed, the pyramidal, or cortico-spinal tract, needs further investigation. Due to the persistent and systematic efforts of Lassek in recent years it has been shorn of its simplicity until now it is known to be not a specific path from Betz cells to anterior horn cells, but a collection of paths of at least diverse origin, perhaps of diverse destination. There is still debate about the very existence of a rubro-spinal tract in man, and the great number of "extra-pyramidal" pathways still resists analysis. Descending paths for visceral control are almost completely unknown, though some knowledge of the ones concerned with the control of sweat glands has lately been obtained.

\section{PERSONNEL}

For any and all developments in neuroanatomy new students are needed. Most investigators in the field are attached to departments of biology in universities and to the departments of anatomy in schools of medicine. However, only a small portion of the graduate students and staff of these departments becomes related to neuroanatomy. Fellowships and adequate financial support for teachers and investigators directed toward the neurobiological field would do much. Support for projects in research is more readily obtained today than support for men in training, and the real need in this as in other fields is for trained men.

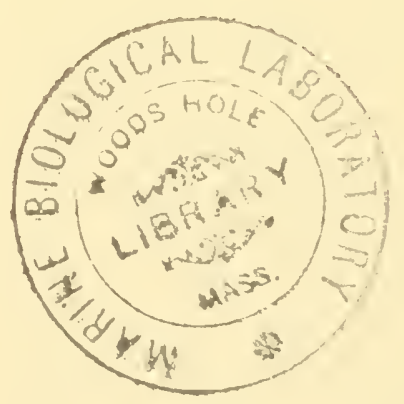




\title{
NEUROPSYCHOLOGY
}

\author{
By Karl S. Lashley \\ Yerkes Laboratories of Primate Biology and Harvard University
}

The ultimate purpose of studies of the nervous system is to gain a better understanding of the mechanisms of behavior. However, neural anatomy and physiology have developed in alliance with medical science; psychology has only recently escaped from administration with philosophy. There has been relatively little direct contact between students of the two disciplines. In consequence, many investigations and interpretations in neurology fail to consider the problems that are raised by complex behavior. Conceptions of integrative mechanisms tend to be oversimplified and of little aid in understanding the major problems of psychology. Psychological studies too often fail to recognize the limitations set by neurological facts and make frequent use of explanatory conceptions, such as that of free nervous energy, for which no physiological counterpart exists. There is a mutual dependence between psychology and neurophysiology. Psychology can formulate descriptive laws of behavior, but the explanation of those laws must be sought in the activities of the nervous system, and the laws must be consistent with the facts of neurology as well as of behavior. The student of neurology must take into account the integration of the whole organism, as revealed by behavior, as well as the functioning of partial systems.

There is thus an urgent need for closer integration of studies of the nervous system with studies of behavior, for more frequent contacts and exchange of ideas between investigators in the two disciplines, and especially for the training of investigators who will have an adequate appreciation of the problems in the two fields.

\section{COOPERATIVE RESEARCH}

Research on the borderline between neurology and psychology requires an integra- tion of numerous specialties; neural anatomy and histology, physiology, psychological techniques of measurement, and frequently biochemical, endocrine, neuropathological, and clinical methods. No one individual can be competent in the techniques desirable for such investigations. Team work is becoming a requisite of investigations in neuropsychology just as it has been found essential in clinical diagnosis and many branches of medical research. Such team work is always expensive and considerable sums must be available to make it possible. At the present time there are not more than five institutions in America in which there is definitely organized experimental research combining neurological and behavioral studies, and even these are heavily weighted toward one side or the other.

In clinical neurology also, although the need for coordination of neurological and psychological studies is receiving some recognition, especially in connection with the lobotomy problem, adequate provisions for psychological studies of patients have been made in few places.

Cooperative research requires more than provision of funds and employment of specialists. There must be stimulating and insightful leadership; this is the greatest lack in the borderline field between neurology and psychology. Few individuals have broad training and comprehension of the problems in both fields. The primary need of neuropsychology is some provision for development of leadership in research.

\section{STUDENT TRAINING}

Except for the highly specialized fields of sensory physiology there are few places in the country where a student is likely to be encouraged to work in the borderline field between neurology and psychology 
and where he can receive adequate training in both disciplines. This is not a question of courses or opportunity for study. Courses in neural anatomy, physiology, and psychology are offered in many places. But the departments are usually as separate as if in different institutions, and students are encouraged to specialize within departmentalized boundaries rather than to cross departmental lines. The history of science indicates that borderline fields are likely to develop only when interest is directed to them by some outstanding discovery or through the application of new and promising techniques. Nevertheless the tremendous progress of studies of sexual physiology and sexual behavior under the support and encouragement of the National Research Council Committee for Research in Problems of Sex shows what can be done toward developing a neglected field by the wise administration of limited funds. In the beginning adequate support was given to a few investigators whose work seemed promising. Important results of their work aroused general interest, attracted additional investigators, and led to special training of students for work in the field.

It is doubtful that any direct means, such as support of special instruction or of fellowships, will contribute greatly to the development of the borderline field. Encouragement of research and successful outcome of the research is the more promising method of developing interest and eventual leadership in the field.

\section{GENERAL PROBLEMS}

Attempts to find explanation of behavior in terms of neurology have been largely restricted to studies of localization of special functions. Although of diagnostic value, such localization has little or no explanatory value; the conclusion that the cortex of the angular gyrus is especially concerned in the use of language throws no light on the physiology of language structure. The concept of the conditioned reflex was an attempt at real explanation but is as inadequate as was the association psychology of J. S. Mills, upon which it was modeled. Psychological analysis of functions is approaching a point where the problems of neurological correlates can be more clearly formulated, Psychological processes can be described as structure having definite organization or relations among elements. Thus perception is the organizing of sensory elements in certain definite ways. The task for neurophysiology is to discover the mechanisms which produce such organization. With such an approach it is possible to foresee at least the kind of physiological explanations which will account for the organization of adaptive behavior, for the structure of language and thought. Such a goal is far removed, but some directions of research can be sketched which have special relevance to the problem.

Evolution of Structure and Behavior. Comparative anatomists have worked out in some detail the evolution of nervous structures. Although in general the degree of centralization and the size and complexity of the central nervous system correlate roughly with the level of behavioral development, it is not possible to specify the structural characters responsible for various phases of behavioral evolution. The chief lack is of a comparative psychology comparable to comparative anatomy. There are comprehensive studies of the behavior of the rat, of the chimpanzee, and of man, but little is known of any other species. Capacity for simple learning has been tested through a wide range of forms, but even for this function quantitative data are lacking or not suitable for comparison of species. There is need for systematic studies of the development of many behavioral characteristics throughout the evolutionary series, with comparable techniques applied at different levels, before insight into the neural basis of behavioral evolution will be possible.

Genetics of Nervous Structure and of Behavior. Studies of inheritance of behavior traits have been most successfully carried out on pathological conditions because of their more certain indentifiability, the weight of medical interest and support, and the availability of medical records. 
Marked recent advances have been in the heredity of dementia praecox, epilepsy, and in analysis of the basis of some hereditary nervous diseases as defects of protein metabolism. Studies of normal traits such as those carried out by the Eugenics Record Office early in the century have been relatively sterile because of the vagueness of the conceptions of mental traits and the lack of exact quantitative measurements. Recent development of more adequate measures of "primary mental abilities" and of personality traits will make possible a more significant approach to the problems of inheritance of individual psychological differences.

The question of the neural correlates of inherited traits has scarcely been touched. The 1920 monograph of Karplus gives some evidence of the inheritance of minor variations in gross nervous structure. Recent studies have shown marked variations in the histological structure of the thalmus and cerebral cortex within an apparently normal population; structural differences which should result in behavioral differences. No attempt has been made to correlate such individual variations in structure with behavior, except in the case of cell deficiency in idiocy. The whole problem of the heredity of nervous structures and their influence on behavior is practically untouched. Such investigations will be difficult and laborious but methods are available and results should repay the investment.

Neurological Basis of Instincts. Among the most difficult problems of the genetics of behavior is the inheritance of specific modes of action, as illustrated by the species-constant patterns of the webs of orbweaving spiders and the recognition of members of their own species by many insects, birds, and mammals. Even for man there is some evidence of an innate perceptual structuring of certain stimulus patterns and further investigation may perhaps reveal a wider range of human instinctive behavior than is at present recognized. The relations of sexual behavior to spinal and cerebral functions and to hormonal activation has been partially analyzed, and these studies set a pattern of investigation that may profitably be applied to other instinctive behavior. However, the fundamental problems of the nature of the reacting mechanisms and of the mode of action of the sex hormones in inducing behavior remain unsolved.

As a preliminary to the neurological analysis of instinct, exact studies of the nature of the stimuli effective in initiating behavior and of the motor patterns elicited must be made. The majority of studies of instinct have been in terms of the products rather than of the behavior. Especially important contributions of this sort have been made by Lorenz and his students. These studies are laying a foundation for neurological analysis, but as yet no attempt toward neurological correlations has been made by the group.

Sensory Physiology. The interest of psychologists in sensation led to the early development of methods for studying sensory processes and of physiological theories of sensory mechanisms. As a result, knowledge of the physiology of vision, audition, and vestibular functions is far in advance of any other aspect of neuropsychology, with techniques so refined that specialization in these fields almost precludes work on more general problems of neurology. The application of electrical recording methods to analysis of sensory pathways and propogated impulses has given additional impetus to work in the field, so that the number of investigators engaged is perhaps out of proportion to the relative importance of the topics. The study of other sensory mechanisms, taste, smell, kinesthesis, touch and pain, have lagged far behind, in part as a result of the greater difficulty in controlling the stimuli, in part because of probably more complicated and less sharply defined neural mechanisms. The practical value of studies of vision, audition, and vestibular functions has been demonstrated, especially in connection with military problems, so that research on these topics is receiving increased support. The need is for support of research on the more obscure sensory processes.

Dynamic Functions. In studies of be- 
havior there is frequently evidence of correlated variation in the level of activity of a number of functions. The organism may be more or less physically active, perceptually alert, emotionally depressed or excited, intellectually indifferent or curious. Such variations have led psychologists to postulate some general stores of nervous or mental energy, which may be directed into diverse activities. Such postulates are represented in the psychologist's notion of "drives," in the psychoanalytic theory of free libido, in Henry Head's conception of reduced vigilance in brain injury, and in Spearman's theory of the G factor in intelligence. In the facts revealed by studies of neurophysiology there is no clear correlate for such dynamic concepts. The nearest approach to a neurological theory of the dynamics of behavior is the HeadCannon theory of thalamic facilitation in emotion. This has been shown to be untenable as an explanation of the dynamic aspects of emotion.

Because of the prevalence of such ideas in psychology there is great need for a systematic investigation of the possible neurological and endocrine basis of individual differences in the level of activity. Studies of frontal lobe function both in experimental work and in human prefrontal lobotomies suggest a possible approach to this problem, but the data so far available are inconsistent and uninterpretable. Recent work on the action of the reticular formation suggests a mechanism for general facilitation, but its bearing on problems of behavior is still obscure. Biochemical and hormonal studies perhaps offer a more promising direction of attack.

Temporal Organization of Action. Investigations of tonic reflexes and of posture have advanced understanding of the spatial organization of the nervous system and of reactions. In contrast, practically nothing is known of the mechanisms by which a predetermined series of acts is carried out or a succession of stimuli, such as a musical phrase or a sentence heard, is condensed into a unitary perception. Yet almost all behavior is based upon such temporal organization. In clinical neurology under- standing of apraxia and of syntactical aphasia or agrammatism depends upon a knowledge of the normal mechanisms of serial action. The mechanism of serial ordering is perhaps the most neglected and, for understanding of complex adaptive behavior, the most important problem in the physiology of the nervous system.

Neurological Basis of Learning and Memory. Since the pioneer studies of Ebbinghaus 75 years ago, thousands of experimental investigations of learning have been reported, yet real understanding of the nature of the memory has scarcely advanced. "Laws" of learning have been formulated, to all of which there are contradictory facts, and scores of theories proposed which are inconsistent either with some facts of learning or of neurophysiology. As in other fields of psychology it is increasingly evident that apparent contradictions of fact will be cleared up only when the neurological mechanisms underlying the processes are understood. At present there are no very promising methods for investigation of the neurological basis of memory. The conditioned reflex experiments of Pavlov are scarcely more than a repetition of the old psychological experiments on association; attempts to discover memory centers or to trace associative paths have been unsuccessful. Theories of memory as a chemical sensitization have little factual support and techniques for testing them are not available. There is little that can be done to advance this topic, pending development of some new experimental approach.

Neurology of Intelligence; Analysis of Defects Following Cerebral Injuries. The vast literature on aphasias, agnosias, personality changes, and other results of cerebral injury contains few really competent studies of the psychological changes involved. Psychological examinations have usually been unsystematic, unreliable, and without adequate normal controls. A review of the tests used, even in the elaborate study of aphasia by Weisenberg and McBride, which is by far the most competent investigation of the subject that has been made, reveals that some of the tests 
which were regarded as diagnostic are frequently failed by normal individuals with a high record of academic attainment.

Attempts to analyze intellectual defects have usually followed the pattern of a facultative psychology differing little from that of Gall. Recent investigations of psychological variables have shown that the diverse functions which contribute to intellectual achievement, to facility in language and in manipulation, are not defined by the logical categories of faculty psychology but have a different pattern which is being analyzed by statistical studies of "primary abilities." There are suggestions that the disassociation of functions produced by brain lesions follows the pattern of these primary abilities rather closely and that a key is provided here to an understanding of the actual physiological mechanisms which contribute to intellectual functions.

The analysis and measurement of personality differences has not progressed as far as that of intelligence, but various standardized procedures in addition to the psychiatric ones have been developed and can be profitably used.

There is rarely opportunity for anatomic control in human patients whose behavioral defects have been studied adequately. Animal experiments provide for better anatomic control but do not permit of equally thorough behavioral studies or of studies of the higher levels of integration that are restricted to man. The number of investigators working with this technique is very limited. Primate material is expensive both to purchase and maintain, and adequate anatomic controls require additional facilities and usually the collaboration of a competent neuropathologist. Experimental studies from those of Fritsch and Hitzig to the frontal lobectomies of Jacobsen have had a significant influence on the development of clinical neurology. The importance of additional support for such work can scarcely be overestimated.

Uniform Study of Clinical Material. The thousands of case histories of effects of brain damage present a discouraging con- fusion in description and interpretation of symptoms and localizing signs. There is rarely either an adequate psychological examination or anatomic control. Cases of aphasia or agnosia which would be invaluable for the evidence which they might throw upon brain functions routinely pass through neurological clinics that are not equipped for adequate psychological study and are reported inadequately, if at all. Notable exceptions to this criticism are the studies of Goldstein and Gelb, of Poppelreuter, and of Head and his collaborators after the first world war, and more recently of Weisenberg and McBride. A few neurological clinics are recognizing the value of psychological as well as of neurological study of the patients and are doing pioneer work in the development of methods; but there is need for a wider recognition of this research field, the employment of adequately trained personnel, and the adoption of more uniform examining methods for the detection and measurement of intellectual defects and of personality disorders. The development of organized teams for neurological and psychological study of patients is a requisite for advancement of studies in clinical neurology.

\section{PUBLICATION AND BIBLIOGRAPHIC SERVICES}

Psychology has better provision for publication than almost any other science. Ten journals and two monograph series of national circulation are published in the United States. In addition are at least three monograph series published by universities. Four of the journals and the two monograph series accept articles in physiological and neurological topics. There is no difficulty in prompt publication of any worthy article. An excellent bibliographic and abstract service is provided by the Psychological Abstracts, covering quite well the fields of neurophysiology, clinical neurology, and psychiatry as well as of psychology.

Publication in neurology is less well provided for. Five American journals of national circulation provide for anatomic, experimental, and clinical material. Provision 
for publication of critical reviews and theoretical interpretations is inadequate, however, and abstract service is limited.

A valuable supplement, to the psychological literature is the Psychological Register, compiled by Carl Murchison. It con- tains brief biographies and complete bibliographies to the date of its publication of practically all active research psychologists in the world. A similar compilation of workers in neurological sciences would be of inestimable value. 


\title{
BASIC AND APPLIED SCIENCE IN THE FIELD OF NEUROLOGY
}

\author{
By Wilder Penfield \\ Montreal Neurological Institute, McGill University
}

THE UNSOLVED problems in the field of neurobiology are a challenge to scientist, clinician and humanitarian. Within the nervous system are millions of neurone circuits. In them throbs the essential energy of life. Through them the body and the mind alike are controlled, and sensorimotor mechanisms are coordinated and integrated in such a way that conscious thought and direction of human activity are possible. In common parlance, the nervous system is the meeting place of body and soul, and the future history of mankind may depend in some degree upon more effective study of this relationship.

The analysis of neurone mechanisms within the nervous system has only begun. Rapid advance in this most difficult field is possible now if better coordination can be established between basic science and clinical medicine. That coordination would develop a new field of applied neurobiological science.

Neurobiology may be considered under three headings: basic sciences, clinical departments and applied sciences. Writing as a clinician, I must look upon the basic sciences from the point of view of their importance to man's own internal mechanisms.

Basic Sciences. Among the basic sciences concerned, a clinician thinks first of the following: biology, chemistry and physiology of the nervous system, electronics, nenroanatomy, neurocytology, neurohistology, embryology, genetics, and also psychology, which may be a basic as well as an applied science. There is little for me to say about these departments except that advance in clinical medicine depends upon their development.

Much of the basic work is best done in protected university departments. It is obvious that, in order to be effective, basic science must be pure, pure in the sense that workers in the field are allowed to follow clues to possible discovery wherever these paths may lead and without necessarily considering the ultimate practical application of the knowledge gained.

Nevertheless, great stimulation may come to the basic scientist however "pure" he may be if he can have close association with the workers in other departments. It may prove to be a healthy influence also if the true scientist is exposed to some contact with clinicians and their problems. This interrelationship can be brought about, in some cases, only by rearrangement in university laboratories and hospitals so as to provide actual juxtaposition of related groups to each other and to groups of patients.

Clinical Departments of Neurobiology. No one man can any longer acquaint himself completely with current contributions to more than one field, and thus the horizontal partitions of the "healing art," that existed in a past not wholly forgotten, between the physician who thought much and did little and the surgeon who did much and thought only by special permission, is no longer adequate.

Inevitable specialization is rapidly changing the organization of the field of medicine. The controlling force that is bringing about this change is the need of the patient. His need is for a physician who understands all the recent knowledge in regard to one at least of the systems of the body; a physician who may or may not also be able to operate when required but who adds to his specialized knowledge familiarity with the basic science in his field. And yet it is essential for the patient that his physician should not be narrow in his specialism, not a man who while 
contemplating one organ becomes oblivious of function in the others.

Finally, the good physician knows that special knowledge is not enough. The human being under his care needs sympathy and understanding as well. Consequently, busy with many demands on his time and thought, the specialist must have the scientist close at hand to help him in his specialty.

There are two major departments of medicine which deal exclusively with affections of the nervous system at present: neurology and neurosurgery, and psychiatry. In each there is an enlarging field for basic science.

Institutes of Medicine. There is only one solution for the over-all problem of medical centers where leadership, scientific and clinical, is expected. That solution is the establishment of institutes of medicine.

In 1875, a youthful botanist, ${ }^{*}$ histologist and physician, by the name of William Osler, was appointed Professor of the "Institutes of Medicine" at McGill University. At the time of his appointment he was teaching histology and physiology and spending long hours labouring at pathology in the autopsy room of the Montreal General Hospital. In due time Osler turned from his effort to learn all the existing basic biological science and focused his attention on diagnosis and therapy. That was the evolution of a great physician and leader of thought in clinical medicine seventy years ago.

But today the story is a different one. There is still need for the internist, the universal diagnostician, but he must be flanked by specialists in treatment and diagnosis. It is still best to give these men preliminary training in basic science, but now even the most energetic can master no more than one field and to be effective in it he must develop a team of workers.

The word "institute" should be given a new definition. A clinical institute is a group of men who study and investigate the problems in a specific field and who

- Osler had been offered the Chair of Botany at McGill in 1872. treat patients in that field. A neurological institute or a psychiatric institute may be constituted by a group of clinicians who treat and study the diseases of the nervous system on the one hand and the mind on the other. But if the clinical group is to deserve the name of institute, there must be added workers in basic science, men with an adequate training who are willing to take the patients' need as guide in the selection of their problems. This addition creates a new classification of workers, workers in applied science.

Applied Sciences. It is obvious that science must be brought to the bedside or into nearby laboratories. In the case of neurology and psychiatry, the applied scientist may some day show us that there is no difference in the two fields, that the cause of mental derangement and normal intellectual processes may be understood in terms of abnormal and normal brain function, and so the two fields will one day merge into one. Psychiatry and neurology will be one specialty and not two, and the therapy will be discriminating and effective. Crude surgical ablations will have disappeared on the one hand and fumbling psychoanalysis on the other.

This therapeutic utopia may seem very far ahead of us, but wise medical educators should recognize now that the basic science of the one department does not differ from that in the other, and much of the basic training of neurologist, psychiatrist and neurosurgeon should be the same.

Workers in applied science may be full time laboratory men, but more often they should also be part time clinicians. The latter arrangement may introduce a little lower level of excellence into their laboratory work. But that is more than balanced by the fact that each man is able to turn from the bedside to laboratory bench and back again with greater insight in each of the two spheres of study.

Applied biological science is different in some respects from basic science and it is certainly different from the art of the practice of medicine. But applied science can provide the indispensable bridge between these two great departments of hu- 
man endeavor. Applied science alone justifies the action of any clinical group in applying to themselves the term "institute." It demands that each group should be housed in a separate building where patient and laboratory are close together and yet not divorced, nor removed too far from other departments of hospital or medical school.

Such a building is no more than the house of the Institute. It provides the best arrangement for a scientific approach to the healing art. But that combination of medicine and science can also be brought about by discriminating segregation within existing buildings. There is one prerequisite, however, the maintenance of a clinical institute calls for annual financial outlay on an entirely new scale.

Neurological and Psychiatric Discase. Understanding of disease of the nervous system depends upon an understanding of the normal function in all forms of life and during various stages of development. Clinicians should therefore draw heavily on knowledge in the whole field of neurobiology. They must not be isolated in their thinking. They need frequent consultations with experts in all the biological sciences.

On the other hand, workers in biological science have also somcthing to gain from this close association. Autopsy material or a spccimen removed from the brain of a living patient at operation may prove a key to important advance in the hands of well-traincd neuroanatomists, provided the subject can be studied psychologically before and after the removal. Or the op- portunity may be one for the chemist, the pathologist, or the embryologist.

Similarly, abnormal behavior in man may be related to chemical abnormalities and may be compared with behavior in subhuman forms. This type of study benefits patients and stimulates scientific advance in laboratory and ward.

Conclusion. Modern medicine demands that workers skilled in the basic sciences be established in close association with neurological and psychiatric departments. There is a mounting need for the establishment of fellowships in all of the basic sciences of the field of neurobiology. Such fellowships should be used for study of neurophysiology, neuroanatomy, biochemistry, psychology, etc., in those laboratories. But fellowships in the basic sciences should also be available for such work in the elinical departments of psychiatry and of neurology and neurosurgery and of endocrinology.

Adequate intellectual liaison means reorganization. It means the establishment of a closer relationship between existing university departments, or the support of special scientific units in clinical departments, or the provision of fellowships for the study of basic science in the cinical departments. It also means that clinical psychiatrists, neurologists and neurosurgeons should be trained in one of the diseiplines of neurobiological basic science. It means that basic scientists should be introduced to the need of the patient and to the illuminating experiments which disease inflicts on man. Only under such leadership ean scientific and therapeutic work go forward effectively. 


\title{
SURVEY OF GENETIC NEUROLOGY
}

\author{
By Paul Weiss \\ University of Chicago
}

The content and conclusions of the following report have been derived from five main sources: (1) the author's personal experience; (2) a symposium arranged by the Committee on Neurobiology (appendix A); (3) a survey through questionnaires (appendix B); (4) a survey of the pertinent literature resulting in a comprehensive bibliography (appendix C); (5) an international conference, held in Chicago March 25-26, 1949, under the auspices of the International Union of Biological Sciences (UNESCO), published as a separate volume GENETIC NEUROLOGY, University of Chicago Press, 1950.

The term "genetic neurology," as used in the following, designates a discipline devoted to the study of the development ("genesis"), growth, differentiation, maturation, maintenance, heredity, aberrations, regeneration, and adjustments of the nervous system, including the neural basis of behavior; especially, the causal analysis of the factors and forces involved.

In contrast to the well established disciplines of neuroanatomy, neurophysiology, and psychology, dealing with the structure and operation of the mature nervous system, genetic neurology does not yet constitute a systematic field of its own. As indicated in the above definition, genetic neurology has areas in common with anatomy, biochemistry, cytology, embryology, genetics, histology, neurology, pathology, physiology, psychology, and surgery. In the study of the development of the nervous system itself, the prevailing approaches have been descriptive and comparative, while the causal analysis of the described phenomena has not yet been undertaken on a scale commensurate to the importance of the field.

\section{CONTENT}

The Following listing of topics circumscribes roughly the subject matter and problems of genetic neurology. The list is tentative and incomplete, but adequate for the present purpose.

A. Embryonic determination of the central nervous system.

1) Induction of neural development; regional differences; species differences; symmetry.

2) Progressive differentiation of the central nervous system (localization of parts; effects of surrounding tissues; shifts).

3) Abnormalities (spina bifida; hydrocephalus; cyclopia; anencephaly).

B. Morphogenesis of the central nervous system.

Factors determining form and architecture of brain, spinal cord, ganglia, placodes (differential folding; fissures; gyri; segmentation; confining action of meninges and skull; origin and morphogenetic role of cerebro-spinal fluid; shape of ventricles; lamination of wall).

C. Cytodifferentation in the nervous system.

1) Speciation of cell types (dichotomy of neuroblasts and spongioblasts; microscopic, submicroscopic and chemical criteria of speciation; pathological, pharmacological and immunologicàl criteria).

2) Affinities among different cell types (association between nerve fibers and sheath cells; selective connections with receptor and effector organs; se- 
lectivity of intracentral connections ).

3) Factors producing changes of specificity (peripheral influences; serological effects; ageing).

4) Neurosecretory processes (development of secretory functions in neural cells; transformation of neural into secretory cells).

5) Myelinization (constitutional differentials between medullated and unmedullated fibers; role of sheath cells; role of functional activity).

D. Quantitative development of the nervous system.

1) Determination of number of ganglion cells (rate of proliferation; rate of specialization; mitotic control; cell migration; degeneration; replacement; sex and species differentials; effect of function on cell number; effect of peripheral connections; hormone effects ).

2) Density of nerve nets (number of collaterals; distribution of endfeet; relation between neuropil and glia; saturation factors).

3) Growth and size of neurons (constitutional vs. exogenous factors in cell size; protein synthesis; functional and trophic effects on cell size; nutritional influences; determination of fiber caliber; limitations of growth capacity; length of neurites; developmental metabolism).

E. Formation of nerve patterns.

1) Orienting factors (direction of outgrowth; plexus formation; "attraction"; pathways; electric influences; neurotropism).

2) Elaborating factors (aggregation; bundle formation; branching; resorption; neuromas).

F. Vascular development.

Relations between nervous system and blood and lymph systems (vascular pattern; functional adaptation to varying oxygen demands; nutrient channels; edema).
G. Regeneration and regulation.

1) Peripheral nerve regeneration (Wallerian degeneration; a xon regeneration; sheath cell transformations; growth rate; effects of age; inhibiting factors; nerve suture; traumatic vs. spontaneous regeneration; differences among different nerves; nerve transplantation).

2) Regeneration in the central nervous system (differences according to species and age; role of ependyma and glia; tumors; synaptic rearrangements; transplantation of ganglia, brain and spinal cord).

3) Non-regenerative regulation (compensatory adjustments of centers after injury).

4) Metamorphosis (morphological and functional transformations in postembryonic stages; hormonal determination; maturation problems ).

H. Trophic effects of nervous system.

(Regulation of tissue growth and maintenance by neural factors; causation of atrophy and hypertrophy; effects on lymphocytosis, capillary permeability, immune reactions).

I. Devclopment of behavior.

1) Origin of reflexes (coordination; role of input; localization vs. mass action ).

2) Development of integrative mechanisms.

3) Development of central automatisms (rhythmic activities; metabolic cycles).

4) Plasticity (homoeostasis; learning; compensatory mechanisms).

K. Genetic aspects.

(Inheritance of neural and behavioral traits; genetic aberrations).

\section{NEED}

The need for intensified and methodical research in genetic neurology is documented by the inadequacy of many of the current basic concepts of the mechanics and phys- 
iology of the development of the central and periphereal nervous system with which present-day neurology is forced to operate. Many current concepts are purely speculative, others are incomplete, still others obsolete. Ample evidence is at hand to show that all phases of neurology, including neurological psychology, would draw fundamental benefits from systematic research and instruction in genetic neurology. The integration of anatomical, histological, physiological, psychological and pathological methods and viewpoints in the study of the developed nervous system is growing steadily. The time would seem ripe to accord to the developing system a similarly integrated treatment.

\section{METHODS}

A most profitable experimental approach to the problems of genetic neurology is offered by the methods of experimental embryology and experimental morphology (e.g., transplantation, deplantation, tissue culture, etc.), in combination with standard techniques of histology, electrophysiology, biophysics and biochemistry. The ability to produce experimental animals with controllably altered nervous and receptor-effector systems of practically unlimited variety, at the same time, creates test objects singularly suited for the study of basic problems of nerve physiology and psychology. The nature of the problems in genetic neurology makes a conjoint anatomical-physiological attack, correlating structural and functional aspects, imperative. Evidence of the fruitfulness of this approach lies in its eminent success in those past instances where it has been used. Proper research objects will have to be chosen from a wide range of animals. While some invertebrates and lower vertebrates offer unique structural and biological facilities for experimentation, other problems (e.g., reeducation after nerve lesion) cannot be properly studied except in man.

Research in genetic neurology is bound to produce results of both fundamental and practical nature. Its fundamental contributions to our understanding of the operation of the nervous system, both normal and pathological, and of the neural basis of behavior are self-evident. In addition, the intensive analysis of growth, differentiation, regulation, etc., of the nervous system would naturally yield fundamental insight into principles and mechanisms of development in general. Causal analysis of the development of behavior patterns will supplement our descriptive knowledge of sequences of developmental steps by insight into the causal linkage and into the relation between hereditary and acquired traits. The practical benefits of systematic research in genetic neurology are well exemplified by the results of war research on nerve regeneration. Likewise, practical directives for rehabilitation after nerve lesions or after orthopedic interventions (tendon crossing, muscle transplantation, etc.) are predicated on better understanding of the scope and the limitations of central nervous plasticity and modes of readjustment, the study of which forms part of the research program in genetic neurology.

\section{PRESENT STATUS}

The present status of the field can, at best, be designated as "undeveloped." While work on some problems (e.g., A, D, E, $\mathrm{G}, \mathrm{H}, \mathrm{I}$ ) has been pushed, at least in part, beyond the pioneering state, other lines (e.g., B, C, F, K) have as yet been barely explored at all. Even in the more active lines, generally speaking, work has been sporadic, sketchy, without the desirable continuity and coherence, inadequate in volume and scope, and definitely not of an intensity or on a seale that would be commensurate with its key role in the progress of neurology. Besides the scarcity of original research, there are also notable shortcomings in the exploitation and correlation of knowledge already available (compare the sizeable bibliography in appendix $\mathrm{C}$ ) and in the mutual exchange and coordination of this knowledge with other neurological disciplines of more advanced status.

These conclusions are borne out by the results of the symposium (appendix A) and of the questionnaire (appendix B). The consensus of the experts present at 
the symposium is illustrated by the following sample quotations.

"While some hopeful beginning in the analysis of this complicated process (i.e., the development of the nervous system) has been made, most of the work remains yet to be done ... The analytical concept of nerve development lends itself to attack by the methods of analytical experimentation and deserves, therefore, a high rating. It leads to concrete experiments, and we have hardly begun to exploit its vast possibilities" (Harrison).

"In reviewing the field of neuroembryology, one is impressed by the scarcity of factual information, and also by the failure to exploit fully the opportunities offered by the experimental embryological methods and techniques for neurological and behavior problems ... The embryologist is not sufficiently informed in neurological details and methods and he usually lacks the conceptual approach of the behaviorist. The only hope for a fruitful progress lies in his cooperation with men trained in neighboring fields" (Hamburger).

"The study of the nerve cell during its enbryonic development is not only of great theoretical interest but is also an important tool in the analytic fractionation of the complex structures and functions of the mature cell. Technical difficulties of such analysis are reflected in the fact that this field is still almost virgin with respect to biochemical or histochemical studies which might illuminate the spectacular morphological changes which separate the neuron from the neuroblast ... It is obvious that this field is wide open for further investigation, and that in addition to the general problems of cell growth and differentiation, many practical problems, such as the regeneration of injured nervous tissue and the action of neurotropic viruses or of neurotoxic drugs await the understanding which might come from such investigations" (Bodian).

"Data of considerable volume exist on various chemical entities in the developing nervous system, but for the most part, they represent isolated observations, and it is well nigh impossible to correlate these into a comprehensive picture for even one animal. Systematic studies on the chemical growth of the nervous system in the embryo and fetus are practically non-existent, a fact which is the more unfortunate since it would seem logical to assume that having more information on the order of appearance and the growth of various chemical constituents and metabolic events in the developing nervous system could not fail to contribute to our understanding of the subtle physiological changes associated with func- tional maturation of the nervous system . . What is clearly needed, in addition to an appreciation of the very great amount of useful information which ean be obtained from studies on metabolic processes in isolated tissues and tissue homogenates, is a elear realization of the limitations inherent in such studies in providing an insight into the way metabolic processes are regulated and ordered in the intact cell or organism. This necessitates a consideration of the importance of mechanisms which regulate the intensity and direction of ehemical processes in the nerve cell. In this field ignorance is almost complete" (Boell).

The questionnaire (appendix B) was sent out to the 61 most prominent investigators in genetic neurology. Of the 51 persons who sent detailed replies, 36 described the state of the field as "unsatisfactory," 3 as "satisfactory," and 4 were "undecided." The following were given as presumable reasons for the "unsatisfactory" condition (listed in the order of weight assigned to them by the group): lack of explicit formulation of the problems; lack of trained persomnel; lack of "appeal" and emphasis in current teaching programs; lack of funds. Only a minority mentioned administrative difficulties (e.g., lack of time or of facilities for cooperative work), or lack of publication facilities. Asked for the existence of courses dealing wholly or in part with genetic neurology, 24 replics (excluding institutional overlap) reported complete lack of such courses, 5 indicated some mention of the subject in general courses, leaving only 6 institutions with an occasional graduate course, and 7 with seminars, devoted to some problems of genetic neurology.

In order to test the degree of community among the workers in the field, the following question was asked: "How many university departments and research institutes in this country could you name in which genetic neurology receives systematic (i.e., more than casual) investigation?" Of 27 answers received to this question (table, appendix B, 5), 23 referred to fewer than 15 , and 17 to fewer than 10 places engaged in such activities. These figures are quantitative supplements to the designation of the state of the ficld as "inadequate." 


\section{PROMOTION}

It is evident that intensified research in the field will automatically produce greater familiarity with its problems and realization of its potentialities, and thus, in turn, attract personnel and funds, which were listed above as being in inadequate supply. It is significant to note, however, that in assessing the presumable causes of retardation, the interrogated group assigned the greatest weight not to lack of funds and trained personnel, but to the "lack of explicit formulation of the problems of genetic neurology," or in other words, to the lack of awareness of the fundamental and practical implications and of the vast needs and opportunities for work in the field. It is to be expected that if and when the field is provided with the missing focus, this fact will of itself produce the necessary impetus, whereupon problems of funds and personnel should gradually resolve themselves.

The answers of the questionnaire regarding remedial measures are wholly in line with this conclusion (table, appendix $B, 4)$. The replies to the question "What measures would contribute most effectively to further invigoration of genetic neurology?", gave about equal weight to "conferences" and "research funds," which clearly expresses the general concern about inadequate articulation and integration of the field. Research fellowships and graduate courses were given a lesser rating. It must be stressed, however, that fellowships granted to individuals competent in one branch of neurology for work on problems or techniques overlapping one or several disciplines related to genetic neurology would add immeasurably to the promotion and diffusion of knowledge and interest in the field.

Specifically, the following measures should be envisaged. (1) A textbook or monographic survey of the field. (2) Periodic conferences among workers in genetic neurology proper and bordering areas. (3) Development of short "workshop" courses to acquaint workers of related fields with basic techniques applicable to research in genetic neurology (comparable to the Cold Spring Harbor courses in "Operative Techniques" and "Phage," or the technical courses sponsored by the Tissue Culture Commission). (4) Compilation of a complete bibliography of genetic neurology. (5) Designation of national predoctoral and postdoctoral fellowships for advanced training. (6) Procurement of research funds. (7) No special measures in the matter of publication seem to be called for at present other than perhaps a bulletin service (mimeographed) for the establishment of rapid information, closer relations, and more extensive communication among workers in the focal and marginal fields.

Genetic neurology emerges not as a new split product in the growing fragmentation of sciences into specialties, but rather as a product of recombination and resynthesis. As such, it is beginning to assume the identity of a separate discipline, and any organizational measures that would aid in its consolidation and maturation would, of course, be beneficial. But the primary need is for men with imagination and perspective. The great opportunities of genetic neurology lie in areas where conspicuous progress can still be made with relatively simple means, hence, at comparatively low expense. The foremost requirement at the moment, therefore, seems to be to attract gifted and resourceful investigators, to impress them with the wealth of existing chances for fundamental discoveries and provide them with adequate working conditions, including sufficient technical personnel. 


\section{APPENDIX A}

\section{CONFERENCE ON PROBLEMS OF THE DEVELOPMENT OF STRUCTURE AND FUNCTION OF THE NERVOUS SYSTEM}

This Confenence was arranged to survey the state of genetic neurology, to outline problems in need of investigation and to indicate promising new lines of attack. It met at the National Research Council building on January 30 and 31,1946 . It was attended by the members of the Committee on Neurobiology and the invited speakers.

\section{LIST OF SPEAKERS AND TOPICS First Session}

(P. Weiss, presiding)

R. G. Harrison (Yale University) : Research on the living nerve fiber.

Viktor Hamburger (Washington University): Embryonic differentiation of the central nervous system (size, localization and interconnection of nerve centers).

E. J. Boell (Yale University): Biochemical ontogeny of the nervous system.

D. Bodian (Johns Hopkins University): Growth, degeneration, reconstitution and regeneration of the neuron.

R. IV. Sperry (Harvard University and Yerkes Laboratories ): Specificities in the developmental relations between centers and periphery.

\section{Second Session}

(K. S. Lashley, presiding)

T. C. Schneirla (New York University): Invertebrate nervous system and behavior.

G. von Bonin (University of Illinois): Evolution of the vertebrate. nervous system and behavior.

Frank Beach (American Museum of $\mathrm{Na}$ tural Ifistory): Instinct and hormonal activation.

F. J. Kallmann (New York State Psychiatric Institute): Heredity in behavior.

Heinz, Werner (Brooklyn College): Child development.
Leonard Carmichael (Tufts College): Embryonic development of behavior.

\section{SYNOPSIS}

Harrison: Review of observations and experiments on nerve fibers in the living state. Outgrowth of axon. Mode of elongation. Rate of advance. Problems of anastomosis. Orientation of growth by structures of the surroundings. No electric orientation. Rejection of chemotropism. Role of Schwann cells.

Hamburger: Early nerve structures anticipating later functional needs. Embryonic induction and morphogenesis of neural plate. Interaction with non-nervous tissues. Lability of determination. Patterns of proliferation in central nervous system. Final numbers of nerve cells. Age difference between dorsal and ventral parts, reflected in phosphatase distribution. Hypoplasia and hyperplasia of brain, spinal cord and ganglia in accordance with mass of peripheral tissue. Recruitment of nerve cells. Developmental influences between nerve centers. Specificity of nerve connections.

Boell: Biophysical and biochemical data on neural tube formation. Changes in cell form. Growth of the brain. Sex differences in growth. Change in water content during growth. Lipid metabolism of the developing nervous system. Increase of phospholipids. Respiratory metabolism of developing nervous tissue. Cytochrome oxidase. Resistance of developing central nervous system to anoxia. Anaerobic metabolism of brain. Acetylcholine and cholinesterase during development. Correlation between chemical activity and overt behavior.

Bodian: Correlation of enzyme activity and cyto-morphological development. Re- 
sistance of regenerating neurons to poliomyelitis virus. Chromatolysis. Variability of cell size with peripheral conditions. Trophic interactions. Protein synthesis in nerve cell. Biochemistry of nerve degeneration and regeneration. Succinic dehydrogenase, phosphatase and cytochrome oxidase activity during regeneration. Continuous replacement growth of neurons and its functional implications.
Sperry: Specificity of neuronal relations. Adaptive vs. maladaptive function. Coordination after confused nerve regeneration. Constitutional differences among neurons. Modulation of nerves by endorgans. Absence of learning in basic coordination. Effects of nerve and tendon crosses. Inherited $v s$, acquired patterns of function. 


\section{APPENDIX B}

\section{SURVEY OF GENETIC NEUROLOGY 1948}

IN ORDEn to obtain an objective cross section of the opinions of the major investigators in fields contributing to genetic neurology, the following questionnaire was prepared. It was first sent to a selected list of key men with the request that they nomtionnaires were then sent to the latter with a similar request, until no further new names appeared in returns. This procedure assured inclusion of practically everybody thought to have first-hand experience and opinions in the matter.

Total of questionnaires sent out: 61 Total of questionnaires returned: 51, (84\%)

\section{QUESTIONNAIRE}

1. Do you think that research in Genetic Neurology is proceeding at a satisfactory rate (as compared to other neurological fields) or is it lagging behind other fields?

$\begin{array}{ccc}\text { satis- } & \text { unsatis- } & \text { un- } \\ \text { factory } & \text { factory } & \text { decided }\end{array}$

$\begin{array}{llll}\text { Number } \ldots . . . . & 3 & 36 & 4 \\ \text { Per Cent } \ldots . . . . . & 7 & 84 & 9\end{array}$

2. If you believe that progress has been inate additional persons to be polled; ques-

unduly slow, mark the presumable reasons on the following list in the order of their weight $(1,2,3$, etc.).

Choices

1. Lack of re-

1st 2nd 3rd 4th 5th 6th $\begin{array}{lllllll}\text { search funds } & 9 & 6 & 5 & 8 & 1 & 0\end{array}$

2. Lack of appeal and emphasis $\begin{array}{llllll}10 & 8 & 6 & 1 & 2 & 0\end{array}$

3. Lack of trained $\begin{array}{lllllll}\text { personnel } & 4 & 15 & 11 & 0 & 2 & 0\end{array}$

4. Lack of publi-

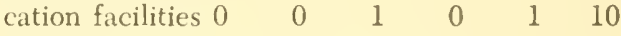

5. Administrative

$\begin{array}{lllllll}\text { difficulties } & 2 & 1 & 3 & 6 & 4 & 1\end{array}$

6. Lack of explicit formulation of $\begin{array}{lllllll}\text { problems } & 12 & 7 & 5 & 1 & 1 & 1\end{array}$

Total weights after assigning descending values to order of preference:

1. Lack of explicit formulation 84

2. Lack of trained personnel 83

3. Lack of appeal 79

4. Lack of funds. 78

5. Administrative difficulties. 44

6. Lack of publication facilities 13

3. Which areas of genctic neurology are, in your opinion, in need of increased support? (Rank in order of need.)

Choices

Sum

1. Descriptive embryology

$\begin{array}{ll}1 & 2 \\ 5 & 5\end{array}$

2. Descriptive histology

0

3. Phylogeny

4. Experimental differentation

() 2

5. Cytochemistry

6. Development of behavior

16

$4 \quad 4$

73

7. Nerve regeneration

8. Neurogenetics 
4. What measures would contribute most effectively to further invigoration of genetic neurology? (Rank in order of significance.)

\section{Choices}

$\begin{array}{llllll}1 & 2 & 3 & 4 & 5\end{array}$

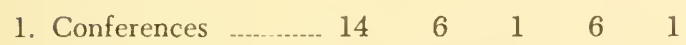

2. Funds $\quad 13 \quad 10 \quad 11 \quad 2 \quad 0$

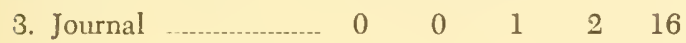

4. Graduate training $\quad 4 \quad \begin{array}{lllll}7 & 9 & 8 & 1\end{array}$

$\begin{array}{lllllll}\text { 5. Fellowships } & \text { _..-.... } & 9 & 17 & 9 & 2 & 1\end{array}$
5. How many university departments and research institutes in this country could you name in which genetic neurology reccives systematic (i.e., more than casual) investigation? (Give total number; enumeration optional).

No. of Depts. No. of Answers

$\begin{array}{cr}0-4 & 4 \\ 5-9 & 13 \\ 10-14 & 6 \\ 15-19 & 3 \\ 20 & 1 \\ & --\end{array}$

27

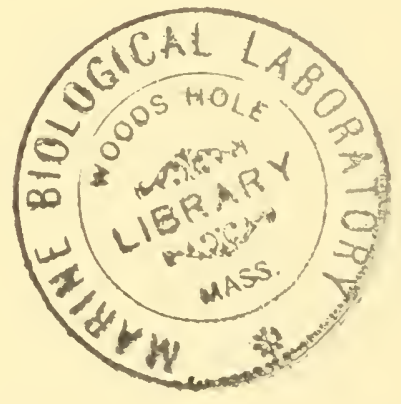




\section{APPENDIX C}

\section{SAMPLE ANALYSIS OF NEUROBIOLOGICAL LITERATURE}

The Following tabulation has the dual purpose of (a) listing the media of publication available for neurobiological work; and (b) determining current trends in neurobiology by an analysis of the content of a single journal (Journal of Comparative Neurology) over three equally spaced 5 -year periods. The data have been compiled under the supervision of the present chairman of the Committee by several assistants. They are accurate within the scope of this survey without pretending to being exhaustive.

Table I lists journals with central interests in neurobiological subjects, Table II journals with marginal interests.

Tables III and IV contain a breakdown of articles published in the Journal of Comparative Neurology during the three 5-year periods 1911-1915, 1926-1930, and 19411945. Table III shows the general trends. Table III-1 gives data on total output, Table III-2 on relative preoccupation with human material, Table III-3 the relative topical distribution, and Table III-4 an index of cross correlation with other fields, as derived from the frequency distribution of bibliographic references.

In Tables IV-A, B and C, an attempt is made to show the extent to which methods of different neurobiological disciplines have been used singly or in combination in each of the 5-year periods; systematic changes in these figures are indicative of collaborative and integrative trends.

TABLE I

Journals With More Than 10\%

Neurobiological, Content

P'ublication

Year No. Vols.

Journal of Experimental

Zoology

Started thru' 45

Physiological Zoology

1904

100

1928

\section{Publication}

Year No. Vols.

American Journal of Anatomy - $1902 \quad 17$

Anatomical Record 1908

Journal of Comparative

Neurology

1898

1898

1939

Annuat Review of

Journal of Cellular and

Comparative Physiology.

19.32

1938

Journal of Neurophysiology

Comparative Psychology

Monographs

1923

Journal of Comparative

Psychology

1921

American Journal of

Psychiatry

1844

Archives of Neurology and

Psychiatry

1919

Journal of Nervous and

Mental Diseases

1874

Journal of Neuropathology and

Experimental Neurology.

1942

Neurological Institute of N. Y.-

Bull.

Psychiatry

Psychoanalytic Quarterly

Psychoanalytic Review.

Psychosomatic Medicine

A.M.A. Section on Nervous and

Mental Diseases.

1906-24

1931-44 12

1938

1932

1914

1939

Los Angeles Neurological

Society

1936

International Clinics

1891-1937

1938-42 5

New International Clinics 1944

Journal of Neurosurgery

Federation of American Societies for Experimental Biol.-Proc. 1942

N. Y. State Dept. of Mental

llygiene-Psychiatrie Quarterly 1927

Johns Hopkins 1Iospital-Bulletin 1890

Diseases of the Nervous System 1940

American Journal of

Psychology

1887

Journal of Abnormal Psychology and Social Psychology _... 1906

Journal of General Psychology 1928
102

10




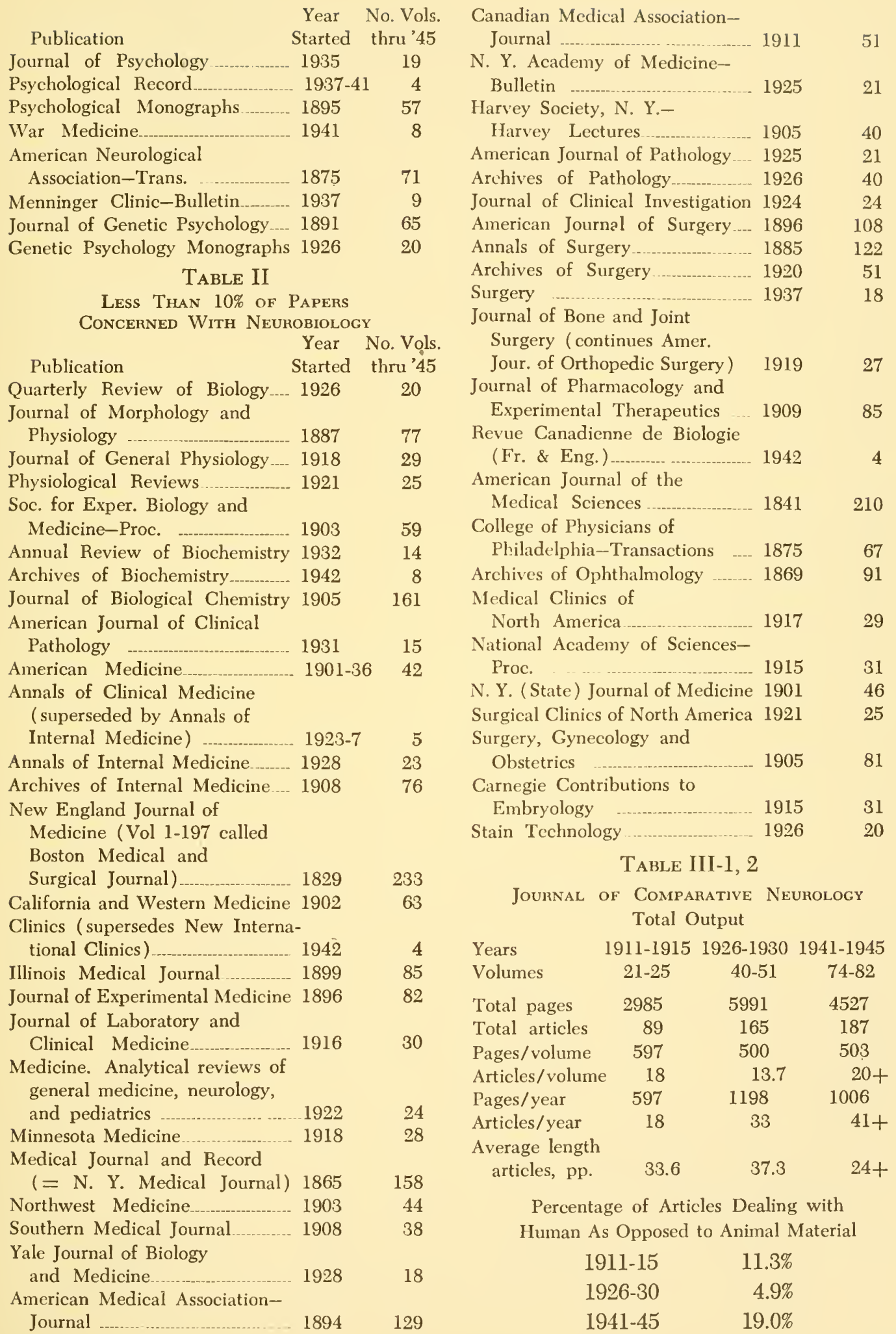




\section{TABLE III-3}

\section{Jounnal, of Comparative Neurology}

Analysis by percentage of total subject matter dealing with specific categories

\begin{tabular}{|c|c|c|c|c|c|c|c|c|c|c|c|c|}
\hline \multirow[b]{3}{*}{ Subject } & \multicolumn{4}{|c|}{$1911-1915$} & \multicolumn{4}{|c|}{ 1925-1931 } & \multicolumn{4}{|c|}{ 1941-1945 } \\
\hline & \multicolumn{2}{|c|}{ Articles } & \multicolumn{2}{|c|}{ Pages } & \multicolumn{2}{|c|}{ Articles } & \multicolumn{2}{|c|}{ Pages } & \multicolumn{2}{|c|}{ Articles } & \multicolumn{2}{|c|}{ Pages } \\
\hline & No. & $\%$ & No. & $\%$ & No. & $\%$ & No. & $\mathscr{F}$ & No. & $\%$ & No. & $\%$ \\
\hline Micro Anatomy & 69 & 77.5 & 2399 & 80 & 131 & 79 & 5004 & 83.5 & 165 & 88 & 2920 & 64.5 \\
\hline Gross Anatomy & 50 & 56 & 1710 & 57 & 42 & 25.4 & 1903 & 31.8 & 15 & 8 & 308 & 6.8 \\
\hline Surgical Meth. & 9 & 10 & 222 & 7.4 & 51 & 31 & 1650 & 27.6 & 70 & 37 & 1561 & 34.5 \\
\hline Electrical Meth. & 1 & 1.1 & 24 & 0.8 & 3 & 1.8 & 133 & 2.2 & 9 & 5 & 194 & 4.3 \\
\hline Physiology & 14 & 15.5 & 290 & 9.7 & 32 & 19.4 & 914 & 15.2 & 38 & 20 & 890 & 19.6 \\
\hline Psychology & 1 & 1.1 & 28 & 0.9 & 9 & 5.4 & 410 & 6.9 & 2 & 1 & 46 & 1 \\
\hline Embryology & 23 & 26 & 743 & 23.8 & 25 & 15.1 & 965 & 16.1 & 33 & 17.7 & 753 & 16.6 \\
\hline Genetics & - & - & - & - & - & - & - & - & 1 & 0.5 & 12 & 0.3 \\
\hline Biochemistry & 6 & 6.6 & 102 & 3.4 & 2 & 1.2 & 20 & 0.3 & 2 & 1 & 48 & 1.1 \\
\hline Geriatrics & - & - & - & - & 1 & 0.6 & 32 & 0.5 & 1 & 0.5 & 8 & 0.2 \\
\hline Endocrinology ... & 1 & 1.1 & 6 & 0.2 & 2 & 1.2 & 52 & 0.8 & 5 & 2.7 & 96 & 2.1 \\
\hline Paleontology & 2 & 2.2 & 60 & 2.0 & 1 & 0.6 & 8 & 0.1 & 1 & 0.5 & 36 & 0.8 \\
\hline Anthropometry & 1 & 1.1 & 30 & 1.0 & 5 & 3 & 252 & 4.2 & 2 & 1 & 54 & 1.2 \\
\hline History and Biog. & - & - & - & - & - & - & - & - & 5 & 2.7 & 71 & 1.5 \\
\hline Total & 89 & & 2985 & & 165 & & 5991 & & 187 & & 4527 & \\
\hline
\end{tabular}

\section{TABLE III-4}

Journal of Comparative Neurology

Analysis of literature cited. References to Journals.

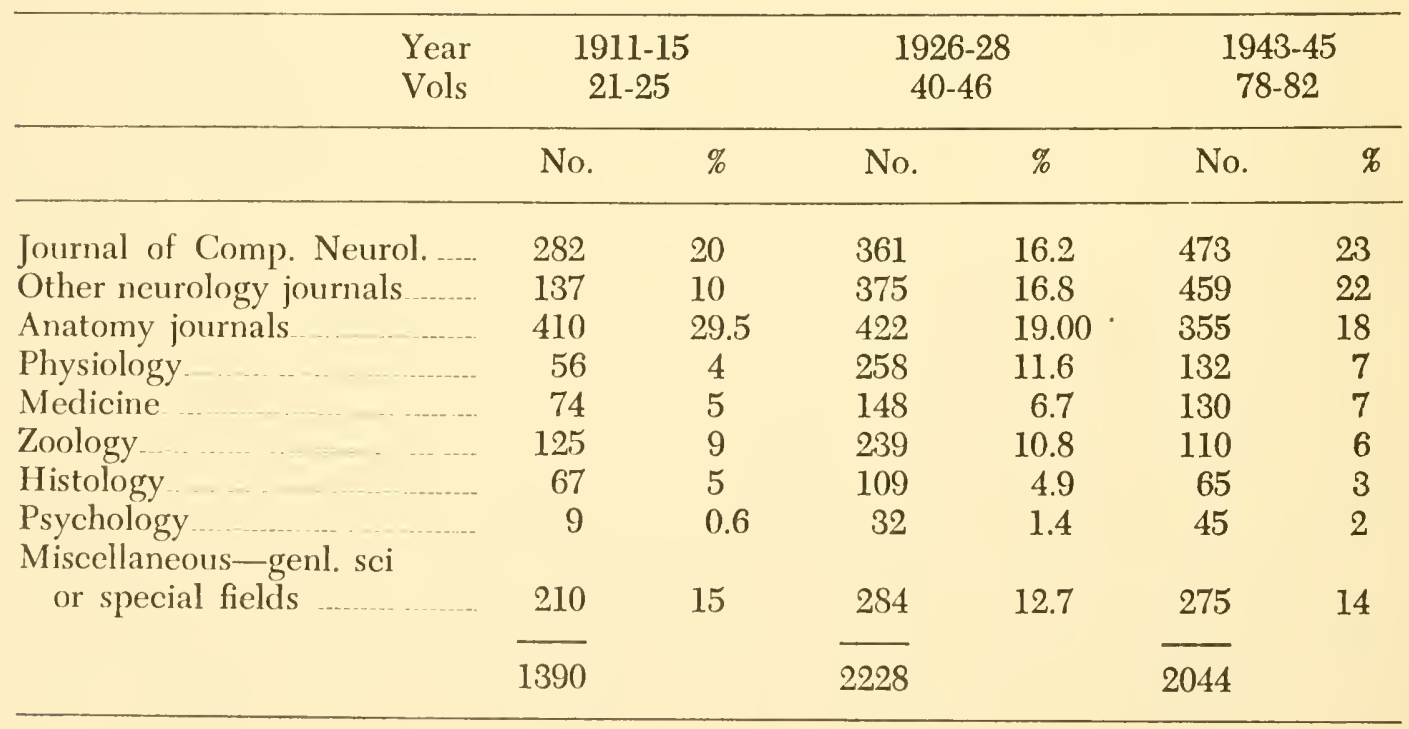


TABLE IV-A

Jounnal of Comparative Neunology

1911-1915 v. 21-25

No. No. Pages \% of

Art. pp. /art. total pp.

1. Microscopic anatomy..19 $388 \quad 20.4 \quad 12.9$

2. Microscopic and gross anatomy $\quad \begin{array}{llll}17 & 1052 & 62 & 35.1\end{array}$

3. Micro. anatomy, sur$\begin{array}{lllll}\text { gical methods } & 7 & 162 & 23.2 & 5.4\end{array}$

$\begin{array}{lllll}\text { 14. Gross anatomy } & 6 & 150 & 25.0 & 5.0\end{array}$

16. Gross anat., paleontology _ $2 \quad 60 \quad 30$

17. Gross anat., anthropometry …...... 130

18. Gross anat., biochemistry _........ $2 \quad 74 \quad 37$

23. Physiology, micro. anat. … $4 \quad 130 \quad 32.5 \quad 4.3$

24. Physiol., micro. anat., surg. methods _....... 132

26. Physiol., gross anatomy $3 \quad 32 \quad 14$

27. Physiol., \begin{tabular}{l|lll} 
biochemistry & 2 & 14 & 7
\end{tabular}

28. Physiol., micro. anat., biochem. 1 - 8

30. Physiol., psychology, micro. anat., embryology _......- $1 \quad 28$

31. Endocrinology, biochem., gross anat. ..... 116

32. Embryology, physiol., electrical methods .... 124

33. Enbryol., physiol., micro. anat. $\begin{array}{ll}1 & 22\end{array}$

34. Embryol., micro. anat.,

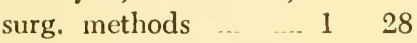

35. Embryol., gross and micro. anat. …..... $\quad \begin{array}{llll}6 & 214 & 35 & 7.1\end{array}$

36. Embryol., micro. anat. $11 \quad 335 \quad 30.4 \quad 11.2$

37. Embryol., gross anat. 29246

TABLE IV-B

Journal of Comparative Neurology 1926-1930 v. 40-51

No. No. Pages \% of

Art. pp. /art. total pp.

1. Mieroscopic anatomy $\begin{array}{llll}58 & 2261 & 39 & 37.8\end{array}$

2. Microseopic and $\begin{array}{lllll}\text { gross anatomy } & 10 & 670 & 67 & 11.2\end{array}$

3. Micro. anat., surgical

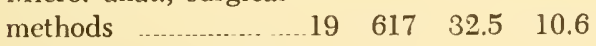

10. Micro. anat., geriatrics 132

13. Micro. and gross anat., surg. methods … $1 \quad 34$

14. Gross anatomy $\quad \ldots \ldots 10 \quad 296 \quad 29.6 \quad 5$
15. Gross anat., surg. and electrical methods ....... 152

16. Gross anat., paleontology

17. Gross anat,, anthropometry

18. Gross anat., biochemistry $\begin{array}{lll}5 & 252 & 20.4\end{array}$

20. Physiology i 12

21. Physiol., surg. methods $6 \quad 124 \quad 20.7$

22. Physiol., micro. anat., surg. and electrical methods _...... $2 \quad 81 \quad 40.5$

23. Physiol., micro. anat. $3 \quad 46 \quad 15$

24. Physiol., micro. anat., surg. methods …...... $9254 \quad 28$

29. Physiol., embryol., psychol. …...... 122

31. Endocrinology, biochenistry, gross anatomy $\ldots \ldots \ldots \ldots \ldots$

33. Embryology, physiol., micro. anatomy ….... 166

34. Embryol., micro. anat., surg. methods ….....-. $494 \quad 23.5$

35. Embryol., gross and micro. anat. …........ $2 \quad 129 \quad 65$

36. Embryol., micro anat. $7 \quad 212 \quad 30.3$

37. Embryol., gross anat. 162

38. Embryol., micro. anat., psychol. $\begin{array}{lll}2 & 76 & 38\end{array}$

39. Embryol., physiol., psychol., surg. methods, gross anatomy …... 1118

40. Embryol., micro. and gross anat., surg. methods $\quad 5 \quad \begin{array}{lll}130 & 26\end{array}$

44. Psychol., micro. anat., surg. methods …... 132

45. Psychol., surg. methods, gross and micro. anatomy …_..... 158

46. Psychol., physiol., gross and micro. anat. 130

47. Psychol., physiol., micro. anat. $\begin{array}{lll}2 & 74 & 37\end{array}$

48. Biochemistry _. 18

TABLE IV-C

Journal of Comparative Neurology 1941-1945 v. 74-82

No. No. Pages \% of

Art. pp. /art. total pp.

1. Mieroscopic anatomy.62 $62704 \quad 11.4 \quad 16$

2. Micro. and gross anatomy $\begin{array}{lll}6 & 120 & 20\end{array}$ 
3. Micro. anat., surg. methods $\begin{array}{llll}31 & 591 & 19.1 & 13\end{array}$

4. Miero. anat., surg. and elect. methods _... $2 \quad 60 \quad 30$

5. Micro. anat., physiol., elect. methods

6. Micro. and gross anat., physiol. ... _.. $1 \quad 12$

7. Micro. anat., physiol., psychol., surg. methods $2 \quad 46 \quad 23$

8. Micro. anat., genetics 112

9. Micro. anat., biochemistry _......... $2 \quad 48 \quad 24$

10. Micro. anat., geriatics $\ldots 1 . . . \ldots \ldots$

11. Micro. anat., endocrinology $\begin{array}{lll}5 & 96 & 19.2\end{array}$

12. Micro. and gross anat, endocrin., surg. methods (.............. 116

13. Micro. and gross anat., surg. methods ..._...... 1

14. Gross anatomy _....... 126

16. Gross anat., palcontology $\quad 1 \quad 36$

17. Gross anat, $\begin{array}{llll}\text { anthropometry } & 2 & 54 & 27\end{array}$

19. Gross anat, physiol., elect. methods _.... 112

20. Physiology $2 \quad 32 \quad 16$
21. Physiol., surg. methods $5 \quad 126$

23. Physiol., micro.

anat. $2 \quad 30 \quad 15$

24. Physiol., micro. anat., $\begin{array}{lllll}\text { surg. methods } & \ldots \ldots \ldots \ldots . . .15 & 412 & 27.5 & 9\end{array}$

25. Physiol., elect. and surg. meth. …........ $3 \quad 72 \quad 24$

33. Embryology, physiol., micro. anat. .......... 140

34. Embryol., nicro. anat.,

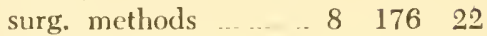

36. Embryol., micro. anat. $20 \quad 461 \quad 23.1 \quad 10$

37. Embryol., gross anat. 118

41. Embryol., physiol. ...... 110

42. Embryol,, physiol., surg. method ........... 124

43. Embryol., physiol., micro. anat., surg. methods _.. 124

49. History and biography $\begin{array}{lll}5 & 71 & 14.2\end{array}$ No. No. pages articles

Total studied _................... 4527 187

No. per volume (avg.) _..... 503

20

Average length of articles, 24 pages

Classifications no. (1), (3), (24) and (36) account for $48 \%$ of total pages.

$19 \%$ of articles deal with humans, others deal entirely with animal subjects. 





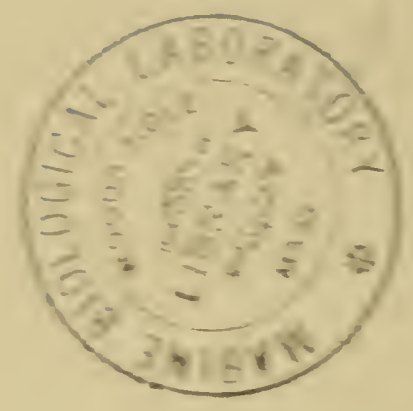

